\title{
JUAN RULFO. \\ DEL PÁRAMO A LA ESPERANZA \\ (ESTRUGTURA Y SENTIDO)
}

A Clara y a sus hijos

\author{
Uno ha creído a veces, en medio \\ de este camino sin orillas, que nada \\ habría después; que no se podría encontrar \\ nada al otro lado, al final de esta llanura \\ rajada de grietas y de arroyos secos. \\ Pero sí, hay algo. Hay un pueblo. \\ JUAN RUlfo, "Nos han dado la tierra"
}

En los cuentos de El llano en llamas (1953) se configuran las tendencias dominantes del mundo de Pedro Páramo (1955) ${ }^{1}$. Las relaciones entre ambos libros se dan en todos los estratos (el lingüístico, el de las figuras y personajes, el del tiempo y espacio en que éstos se manifiestan, el de las huellas de otros textos y contactos con ellos). Afectan tanto la configuración general de la novela como aspectos y detalles menores de la misma: guiños del texto al lector que crean una atmósfera de vasos comunicantes y abren la novela a dimensiones amplias de significación.

1 Para los cuentos utilizo la segunda edición de "El llano en llamas" y otros cuentos (1953), FGE, México, 1955. De la novela he preferido usar una edición relativamente reciente: Pedro Páramo, 2a. ed., rev. por el autor, FCE, México, 1981. La prefiero porque es la más cuidada en la separación de los fragmentos. En todas las anteriores, e incluso en la edición conmemorativa de Bellas Artes que divide los fragmentos con una marca tipográfica (un cuadradito) hay por lo menos un error obvio en este sentido. El detalle es importante para la interpretación de la obra, y ha dado pie a algunas conjeturas críticas, por lo general, poco rigurosas.

De ahora en adelante, citaré ambas obras indicando sólo las páginas donde se encuentra el pasaje citado, salvo los casos en que se pueda prestar a confusión. Las cursivas son mías, excepto cuando se indique lo contrario. 
Destaco, por ahora, sólo algunos rasgos recurrentes y comunes a los dos textos. Los considero fundamentales en el mundo de ficción de Rulfo y en la visión del mundo que éste objetiva.

El modelo de parentesco de la tríada familiar (padre-madre-hijo) subyace en casi todos los cuentos y en Pedro Páramo. La tríada se modifica conforme se destruye un orden patriarcal y opresor preexistente. El proceso, fundador por excelencia, determina el trabajo de la escritura. En los cuentos la escisión del núcleo familiar es la marca textual que indica el inicio de la transformación. Ésta puede darse por la muerte, ausencia o disfunción explícita o implícita del padre ("Talpa”, “El llano en llamas”, “„Díles que no me maten!", "Luvina", cuentos que precisamente ocupan el lugar central del libro).

Rota la relación básica del modelo patriarcal - la díada padrehijo generadora de la vida-, se va desplazando, al mismo tiempo, la función mediadora y relacionante de la madre, quien gradualmente ocupa el centro del modelo (el lugar de la ley). Este desplazamiento de la madre determina un tiempo propicio a las transformaciones y a la regeneración individual y colectiva ("El llano en llamas", "Luvina", "No oyes ladrar los perros"')2.

El proceso implica dos alternativas que no se excluyen entre sí y que, de hecho, se conjugan en Pedro Páramo. Una de ellas es la tendencia a la recuperación de la unidad perdida y la otra es la búsqueda de un nuevo camino.

En "El llano en llamas", cuento central del libro, se logra restablecer la unidad familar después de la escisión, gracias a la madre, y el padre es todavía capaz de sufrir un proceso de cambio positivo. Sin embargo, en el momento mismo de la crisis histórica, dominan los signos de destrucción. Se explica, entonces, que en la novela se prostituyan e inviertan los símbolos constitutivos del mundo patriarcal. De ahí que el aire y el fuego sean sofocantes y devastadores; que las armas que garantizan el dominio se presten al crimen individual y colectivo, y que el hijo (Miguel) en quien se proyecta el padre sea un antihéroe condenado naturalmente a la muerte, y que invierta el sentido de su nombre.

${ }^{2}$ En "Luvina" es evidente este desplazamiento. La madre (Agripina, "el pie que llega primero"), por indicación del padre, es la encargada de encontrar cobijo y alimento para la familia. Ocupa finalmente el espacio sagrado de una iglesia en ruinas donde queda con los hijos y el esposo. "No oyes ladrar los perros" no es tan explícito. Sin embargo, es el recuerdo de la madre lo que impulsa al padre a llevar, a cuestas, a su hijo herido. En el cuento es importante también la luz de la luna (elemento femenino). 
Los cuentos de El llano en llamas ya expresan la tensión entre el mundo ideal y la vida práctica (mundo de las ideas-concreción de la historia), lo cual produce una escisión que entorpece o frustra el ideal y la historia concreta. Esto convierte el deseo en el acicate del proyecto vital. Y al hombre en una criatura deseante y escindida (Macario y Pedro Páramo).

El incesto se perfila entonces como una posible respuesta al vacío. En los cuentos asoma repetidas veces con variantes significativas que indican la búsqueda del modelo para Pedro Páramo ("Macario", "En la madrugada", "Talpa" y "Anacleto Morones"). En “"Macario", "En la madrugada" y "Anacleto Morones", el incesto remite a una tríada familiar alterada: por sustitución (tía que reprime y ocupa el lugar del padre, de la ley, y criada que protege y amamanta en "Macario"; tío por la línea materna que paradójicamente viola y acoge, y madre impotente para la acción, "En la madrugada"). Sin duda en estos relatos ya se intuye lo que en "¡Díles que no me maten!” se explicita: que la orfandad. rebasa los límites de posibilidad de una vida a la altura del hombre.

En la novela, la destrucción de Pedro Páramo está marcada por la orfandad radical, y el incesto (la pareja de hermanos) adquiere caracteres simbólicos y míticos que lo relacionan directamente con la transformación de un mundo en otro y la posibilidad de futuro, como se verá después.

Otro rasgo caracterizador del mundo de Pedro Páramo, que también aparece en los cuentos, es la culpa derivada del crimen colectivo entre hermanos. Esta "marca de Caín" (como la llama Frazer), surge en la vida individual y en la colectiva. "Talpa", "El llano en llamas" y "Luvina', reúnen ambos aspectos, que se integran paradigmáticamente en Pedro Páramo, novela y personaje.

La marca cainítica determina la condición itinerante del pueblo. Sólo que en estas condiciones la escatología cristiana ha perdido su centro. El modelo evangélico se angosta y satiriza. El hombre parece condenado a seguir caminando, y su peregrinar constante es errático e involutivo ("camino y camino y no ando nada...", “El hombre", p. 51; "Y yo comienzo a sentir como si no hubiéramos llegado a ninguna parte", "Talpa", p. 74). En Pedro Páramo se manifiesta el éxodo que implica la muerte del pueblo por efecto de la culpa y de la pérdida del centro, pero se establece un proceso generador de otro tiempo.

Es que se pierden el modelo rector y el objetivo. La tierra prometida se convierte en tierra calcinada, inhóspita ("Nos han dado 
la tierra'"); tierra de muertos, finalmente maldita por la sangre derramada (Pedro Páramo). A su vez, el crimen y la violación de la tierra provocan la inversión total de la imagen de "pueblo escogido". El pueblo peregrino se amontona, se oprime ("Talpa'); la voz colectiva se transforma en "mugido" o "murmullo" sofocante ("Talpa", Pedro Páramo).

Se invierten dos de los nexos sociales más fuertes: la relación de pareja y la función religante de la iglesia (pueblo de Dios), que se transforma, no sin contradicciones, en redes de muerte, desolación y soledad o se cosifica paródicamente en la gran farsa de "Anacleto Morones"3. La primera se ve afectada por la culpa derivada del incesto (camítico en "Talpa', fundador en Pedro Pára$m o$ ), que sustituye al amor, lo cual revierte sobre el sentido de la vida toda.

Del dinamismo se pasa a la inmovilidad progresiva de la muerte ("Luvina", "Acuérdate", "No oyes ladrar los perros" y, finalmente, Pedro Páramo). Como en el José Revueltas de El luto humano (1943), se opera en el texto un cambio de óptica que nos permite presenciar el avance progresivo interno del proceso de destrucción, al mismo tiempo que en la superficie el movimiento se detiene prácticamente.

No obstante, en el caso de Juan Rulfo estamos lejos de un pesimismo totalizador. Aunque el foco de atención se centre en "la caída", ésta se destaca porque su contrapunto vital nunca desaparece del todo. Se condena, sin lugar a dudas, todo un orden de vida que conduce al aniquilamiento del hombre y, en consecuencia, a una muerte sin posibilidades de resurrección (el temor de Macario, el destino de Pedro Páramo). Este orden se asocia a problemas estructurales de carácter social y económico que determinan la destrucción del hombre por el hombre. Pero los problemas estructurales, parecen implicar los textos, no eximen al hombre individual de la culpa. La alteración del binomio hombre-

${ }^{3}$ Es probable que, al escoger el nombre de Anacleto Morones, Rulfo pensara en "Anacleto González Flores, llamado «El maestro", que fue uno de los ideólogos más importantes del movimiento cristero en Jalisco. Como líder defendió, consciente y reiteradamente, a la familia núcleo y base de toda sociedad mayor" (ANDRÉs FÁBregas, "Los Altos de Jalisco: características generales", en José Díaz y Román Rodríguez, El movimiento cristero. Sociedad y conflicto en los Altos de Jalisco, Nueva Imagen, México, 1979, pp. 51-52). Morones es también un apellido asociado a la política de Jalisco desde la Audiencia de la Nueva Galicia a mediados del siglo Xvi; la familia se ha caracterizado por defender los intereses locales, desde entonces (ibid., p. 34). 
sociedad provoca, como en la tríada familiar, el desastre. Las relaciones de solidaridad se sustituyen por las de muerte en un contexto histórico donde priva la injusticia y el egoísmo. Este hecho social se especifica en los textos en torno al problema de la tierra y al proceso revolucionario que marca la época contemporánea en México, al cual se suman los efectos de la primera guerra mundial.

Pero hay futuro en el mundo de Rulfo. Los signos esperanzadores aparecen junto con los destructivos (el trigo y la cizaña). Su óptica percibe las contradicciones y los síntomas de renovación del "reino de este mundo", acorde con un destino trascendente (en el plano simbólico, la anhelada conjunción de cielo y tierra $)^{4}$ que deberá pasar por la depuración y transformación de los procesos históricos.

Tanto en El llano en llamas como en Pedro Páramo la idea de futuro se objetiva, en el estrato de los personajes, en los hijos de la cuarta generación. Sin embargo, los cuentos dejan entrever el riesgo de la semilla contradictoria (el hijo del Pichón en "El llano en llamas"; el joven de "En la madrugada", la interrogación abierta sobre el hijo incestuoso de Anacleto Morones y su hija). En Pedro Páramo Miguel debe morir por ser el hijo en quien se proyecta el padre, mientras Juan Preciado (proyección de su madre, Dolores Preciado) crea una nueva alternativa histórica. Estos aspectos se ampliarán en el análisis.

Como veremos después, la novela hace surgir de la destrucción la posibilidad de futuro, a partir de una transformación radical que modifica las bases mismas del sistema, mediante los símbolos y mitos del mundo de ficción.

No obstante, Pedro Páramo no pretende narrar la historia de ese mundo futuro y por tanto, virtual. La perspectiva desde donde se narra integra la imaginación, el mundo de creencias y el lenguaje simbólico, pero no es abstracta. Se reconoce implícitamente que los mitos, los símbolos y la historia no se contradicen; más bien se complementan y muestran el sentido.

Es extraordinaria la síntesis significativa que logran los cuen-

"En "Luvina", microcosmos de Pedro Páramo, se alude a un centro de calma, justo antes del amanecer, de signo esperanzador: "Pero hubo un momento en esa madrugada en que todo se quedó tranquilo, como si el cielo se hubiera juntado con la tierra, aplastando los ruidos con su peso... Se oía la respiración de los niños ya descansada"' (p. 117). En Pedro Páramo la unión de cielo y tierra impulsa todo el proceso de la transformación del mundo de la caída del hombre, de su historia y de su medio natural. 
tos y la novela al vincular todo el proceso de la vida del hombre con el de la naturaleza. Esto facilita la proyección social en torno al problema de la tenencia de la tierra y la entrada al ámbito del símbolo y de los mitos primarios relacionados con la vida, la fecundidad y los ritos agrícolas, por oposición a los de la muerte.

Como apunté antes, el devenir del hombre y de la historia se vincula con el modo de relación entre cielo y tierra. Así los signos de la caída del mundo patriarcal están ligados a los efectos destructivos de un mundo solar que calcina y erosiona la tierra y condena al hombre a la sed (modalidad del deseo en cuentos como "Nos han dado la tierra") y al fuego destructor ("El llano en llamas"). A ellos se suma el aire en su forma agresiva de viento huracanado ("Luvina", Pedro Páramo). La luna, en cambio, manifiesta el mundo materno, transformador, cambiante, al que se asocian los símbolos regeneradores del agua (lluvia, mar, río).

Según se incline la historia hacia la muerte o hacia la vida, los elementos primordiales se transforman. De cara a la muerte, se desnaturalizan: el aire y el cielo azul se hacen pesados y negros ("Luvina"); el fuego destruye y no purifica ("El llano en llamas"); el agua se tiñe de sangre ("El hombre") y de muertos que propician la caída ("Es que somos muy pobres"); la tierra se calcina y destruye ("Nos han dado la tierra". y Pedro Páramo). Por el contrario, de cara a la vida el aire sopla suavemente, las nubes se desmenuzan, las casas reflejan el sol de la tarde (símbolo materno y masculino a la vez), la naturaleza es pródiga en frutos (cf. por ejemplo, el discurso de Dolores Preciado en Pedro Páramo).

Pero, sobre todo, el devenir temporal adquiere caracteres simbólicos indicativos del sentido último de los acontecimientos en el mundo de ficción. Éstos se marcan con el color del cielo y con el paso de la noche. Cuando cae un mundo, los síntomas de la regeneración vital se asocian a la cercanía del amanecer. Así en "Luvina" (p. 117) y en Pedro Páramo, donde la muerte inminente del cacique ocurre simultáneamente con la llegada del amanecer (p. 151). También la lluvia (símbolo esperanzador de la posible unión entre cielo y tierra) acompaña a los procesos de transformación hacia lo alto. Es el caso de la lluvia persistente que precede y acompaña a la muerte de Susana San Juan.

Asociadas a los momentos claves de la historia personal y colectiva aparecen las criaturas aladas (tordos, cuervos, golondrinas; pero también zopilotes, murciélagos, comejenes). Ellos anticipan el proceso de la caída (los comejenes - de suyo disminuidos- se convierten en gusanos desnudos en "Luvina") 
y acompañan los signos vitales ascendentes como los perros y también las ranas y las gallinas, todos ellos animales portadores de expresiones cósmicas. Así, por ejemplo, el perro se relaciona con los símbolos maternos y de resurrección ("No oyes ladrar los perros", "Nos han dado la tierra") y las ranas se asocian a las "aguas primordiales", también de signo materno ${ }^{5}$ (por eso la madrina de Macario, que invierte la función materna, odia las ranas y obliga al ahijado a destruirlas).

Los pájaros y el viento se hominizan. Sufren transformaciones psíquicas acordes con los procesos históricos y vitales (los pájaros ríen o se burlan en Pedro Páramo; el viento "rasca como si tuviera uñas", arranca y escarba en "Luvina") 6.

Todos estos elementos se manifiestan en rasgos escriturales que tejen la visión del mundo dominante, y objetivan una idea de la historia. En el caso de la obra de Rulfo se crea una tensión entre los hechos de vida y los de muerte. Esto corresponde en el orden formal a un ritmo en contrapunto constante: espacial (arriba-abajo; afuera-adentro); temporal (ayer-hoy); ético (lo alto-lo bajo); ideológico (mundo ideal-praxis histórica); lingüístico (lenguaje poético arquetípico-lenguaje coloquial imperativo y gestual, tendiente al silencio por pérdida). El sentido se manifiesta por el énfasis en uno u otro extremo, según la historia avanza.

El dinamismo vital cotidiano resulta de la tensión progresiva entre vida y muerte. En ese devenir se censuran etapas correspondientes a momentos históricos determinantes (el caciquismo, la injusta repartición de la tierra) o se destacan favorablemente

${ }^{5}$ Cf. Juan Eduardo Cirlot, Diccionario de simbolos, 6a. ed., Labor, Barcelona, 1985, s.v. perro, rana. El libro de Cirlot me parece fundamental para cualquier análisis de la obra que tome en cuenta el sentido y su dimensión simbólica. Es un libro que Rulfo conoció y utilizó, sin lugar a dudas. En su biblioteca particular se encuentra precisamente en un librero pequeño a mano derecha de su mesa de trabajo, hecho que pude constatar en una visita a su casa, y gracias a la gentileza de Clara Aparicio de Rulfo y de sus hijos. Es evidente además que abre el texto e ilumina su significación. Por eso lo utilizo como una de las primeras fuentes en el trabajo. También lo retomaré al analizar la presencia y transformación de otros textos en El llano en llamas y en Pedro Páramo.

${ }^{6}$ Cf. Gaston Bachelard, "El viento" en El aire y los sueños. Ensayo sobre la imaginación del movimiento (1943), FCE, México, 1958, pp. 278-279 y 284. El libro de Bachelard, como el diccionario de Cirlot, me parece muy importante para interpretar los libros de Rulfo, como se deriva de la lectura que hago. No obstante, no he podido comprobar si Rulfo lo conocía personalmente, aunque la evidencia parece demostrarlo. 
otras. La óptica en los textos de Rulfo se centra en el mundo censurado y negado; el sentido, en cambio, busca apuntalar caminos de liberación futura. Es decir, que la perspectiva dominante desde donde se narra rebasa el presente y se abre al futuro, como ya señalé. El hecho es coincidente con la distancia histórica desde donde se narra (el proceso revolucionario abarca de 1910 a 1929; los textos se escriben entre 1945 y 1953, aproximadamente).

Una marca textual que recorre tanto El llano en llamas como Pedro Páramo cristaliza paradigmáticamente la pedagogía de la escritura: el punto de vista. Éste oscila entre la primera persona y la tercera, pero ni siquiera el narrador omnisciente del segundo movimiento en Pedro Páramo rebasa la óptica de los personajes, como se verá después. Más bien se limita a permitirnos oír y ver, al mismo tiempo, varios planos temporales y espaciales. Preocupado por el sentido, su trabajo textual facilitará una lectura simultánea de los tiempos y los espacios, pero éstos no se confunden, de tal manera que individuación y cadena social se complementan una a otra.

Porque remite al sentido, esta concepción del dinamismo textual está ligada - explícita o implícitamente - a todos los estratos textuales. Desde este punto de vista pretendo hacer un recorrido somero por el texto de la novela conforme a la disposición de sus movimientos y fragmentos, lo cual equivale a captar la forma básica de su organización. Queda para un trabajo próximo la elaboración de este principio de escritura en otros estratos. Específicamente me interesa destacar en sí mismo el mundo complejo de los personajes y sus interrelaciones. Ahora sólo me referiré a él en la medida en que contribuye a darnos la visión general del sentido en la novela y la estructura global que la conforma. He reservado también para un futuro próximo el estudio de las relaciones de la novela y de los cuentos con otros textos, tema sobre el que estoy trabajando para finalmente plantear las implicaciones históricas del análisis ${ }^{7}$.

${ }^{7}$ De hecho, ya he adelantado algunas consideraciones sobre ambos puntos en dos artículos próximos a publicarse: "Figuraciones de la Historia. El llano en llamas de Juan Rulfo" y "Juan Rulfo. Del cuento a la novela". 


\section{Estructura y sentido en Pedro Páramo}

\section{Atisbos y vacíos de la crítica}

La crítica suele aludir a lo novedoso de la forma narrativa en $P e^{-}$ dro Páramo. Muchos, como Mariana Frenk, consideran el libro como la primera "nueva novela" de Hispanoamérica. Sin embargo, cuando se habla de su estructura (fragmentada en su secuencia temporal y espacial) los críticos suelen evadirse. Presentan el problema parcial o arbitrariamente, e incluso llegan a negar la existencia de una estructura coherente en el libro.

Considero que basta comentar algunos trabajos característicos sobre este punto. En 1964 Luis Leal publica un breve artículo, "La estructura de Pedro Páramo", que se reproduce múltiples veces después. Lo destaco precisamente por esa importancia que se le ha dado, y porque pretendo abordar este aspecto fundamental de la novela. En realidad la estructura se le diluye al crítico en atisbos que no llega a rastrear en el entramado del texto. De hecho su comentario final es ambiguo. Parecería que la novela es confusa o débil desde un punto de vista estructural y que el estilo se encarga de salvar esa ¿limitación?:

Rulfo [ . . . ] ha tratado de reflejar en la estructura caótica el fondo mismo de la novela, que es en sí vago, indefinido, irreal, nebuloso. Pero unificado por el tono poético, a veces mágico, que ha sabido mantener a través de todas sus páginas ${ }^{8}$.

Un caso diametralmente opuesto, en cuanto a tendencia crítica, es el estudio de la argentina Liliana Befumo Boschi, "Pedro Páramo o el regreso del hombre". Befumo Boschi descifra la novela con base en un análisis estructural y hermenéutico minucioso con aciertos en la interpretación del nivel simbólico ${ }^{9}$. Sin embar-

${ }^{8}$ Luis Leal, "La estructura de Pedro Páramo", en $A L M, 4$ (1964), p. 294.

${ }^{9}$ Véase, por ejemplo, el diagrama de la p. 112; (Liliana Befumo Boschi, "Pedro Páramo o el regreso del hombre", en Violeta Peralta y Liliana Be. FUmo Boschi, Rulfo. La soledad creadora, Fernando García Cambeiro, Buenos Aires, 1975). El estudio de Befumo Boschi es de los pocos que hacen un análisis hermenéutico centrado también en el universo de los símbolos, principalmente cristianos y de la mitología universal. En este trabajo no pretendo contraponer mi crítica a la suya, en beneficio de la economía de tiempo y espacio, pero tengo la certeza de que, si bien coincidimos en el enfoque, nuestra lectura es diversa en aspectos que considero fundamentales. 
go, tal vez en el afán de confirmar ciertas hipótesis, el análisis complejo de la estructura oculta lo que hubiera revelado una lectura más naturalmente apegada a la propuesta de la organización textual.

Sin duda el análisis sensible y atinado de George Ronald Freeman en Paradise and fall in Rulfo's "Pedro Páramo" revela una dimensión clave del libro. No me sorprendió saber que era uno de los textos críticos que le gustaban a Rulfo. Freeman ha sabido trazar en multitud de elementos el universo de la caída en la novela. Sin embargo, pienso que su limitación estriba en no haber captado la complejidad de la visión del mundo concretada en el texto. No percibe el juego necesario entre caer y levantarse (subir-bajar; muerte-nacimiento) en el presente de la escritura. Para él lo alto es algo perdido ya, irremediablemente en el recuerdo. Así define el sentido global al concluir su estudio:

The meaning of the novel, if one can be verbalized, is that the fallfrom-grace is a constant in human experience. The total movement of the narrative is away from wholeness toward disintegration. The characters, in the process, gradually acquire a deepening awareness that original harmony has been irretrievably lost and that all that remain are dreams and memories - pale reminders of an ephemeral, perhaps quixotic movement of completeness in their distant past $^{10}$.

Evidentemente el autor no ha captado las claves del contrapunto que el propio texto indica una y otra vez, como por ejemplo justo al inicio de la novela, en los dos primeros fragmentos. Con una lógica y economía admirables, se nos van marcando los núcleos de significación que apuntan al sentido.

Abre la novela la declaración de Juan Preciado, en primera persona, que indica su acción y el lugar de llegada: "Vine a Comala...". Señala cómo el primer motivo que lo impulsó a regresar fue la promesa hecha a su madre de ir en busca de su padre para cobrarse caro el olvido en que los ha tenido a ambos (p. 7). Promesa que Juan Preciado pensó no cumplir al principio. El impulso decisivo, sin embargo, le llega de repente, que es el modo como ocurren las cosas en el mundo de Comala. O como dice esta primera vez el narrador personaje: "ahora pronto". Y le llega

${ }^{10}$ George Ronald Freeman, Paradise and fall in Rulfo's "Pedro Páramo", C.I.D.O.C., Cuernavaca, 1970, cap. 5, p. 9. 
por el camino profético de los "sueños" y de las "ilusiones". Es un impulso superior al que recibe de la madre todavía viva: "Por eso vine a Comala"' (id.).

El segundo fragmento nos coloca de inmediato en la atmósfera y el tiempo de la narración: "Tiempo de la canícula", "aire de agosto" que "sopla caliente". Indicios todos que se suman al propio nombre del lugar: Comala 'lugar sobre las brasas', según declaración del propio autor"1. Como en "Luvina" el viento se ha desnaturalizado y ha invertido su función aérea, ascendente. Conforme se baja, el calor se intensifica y la actitud, derivada del entorno, es expectante: "Todo parecía estar como en espera de algo" (p. 10). Ha empezado el contrapunto.

Se trata de una atmósfera y un tiempo de carácter solar, llevados a sus connotaciones de efecto más destructor (caída). Es el reino masculino, paterno. Sin embargo, el "olor podrido de las saponarias" es un indicio de signo opuesto. El adjetivo podrido no se repetirá en toda la novela, ni la alusión a las saponarias que alude al acto de limpiar, pues de ellas se hace el jabón. Su presencia se singulariza con carácter simbólico. De acuerdo con la alquimia, un estado de putrefacción es propio del renacimiento de una materia -en el caso de la novela, un mundo- después de la muerte y la disgregación de su escoria. Ese estado suele representarse por "medio de cuervos negros [... ] y otros signos fúnebres" y supone el principio de la "nueva vida"12. Así en el texto de Rulfo, un poco más adelante, al juntarse e identificarse entre sí Juan Preciado y Abundio su medio hermano (guía y mediador entre mundos, ejecutor último de la muerte de Pedro Páramo), aparece una "bandada de cuervos": hombros.

[...] Los dos íbamos tan pegados que casi nos tocábamos de

${ }^{11}$ El propio Rulfo ha definido así el lugar de llegada de Juan Preciado: "Bueno, Comala es un símbolo. Es una rueda de barro donde calientan las tortillas [...]. Es un símbolo del calor que hace en el lugar donde se desarrolla la historia. Esta historia se desarrolla en la Tierra Caliente [...] una región que está entre la altiplanicie, el México del altiplano, y la Sierra Madre Occidental. Allí hay una faja muy grande que casi abarca todo el país y que le dicen la Tierra Caliente. Hace mucho calor y Comala está en medio de esa región. Eso significa que está sobre las brasas. Allí dicen que como si estuviera en las brasas del infierno. En realidad es un lugar muy caluroso", MARÍA HE. LENA ASCANIO, ed., "Juan Rulfo examina su narrativa", en Escritura, 1976, núm. 2, pp. 308-309.

${ }^{12}$ J.E. CiRLOT, op. cit., s.v. putrefacción. 
-Yo también soy hijo de Pedro Páramo- me dijo.

Una bandada de cuervos pasó cruzando el cielo vacío, haciendo cuar, cuar, cuar (id.).

Los hermanos quedan vinculados a esa posible transformación del mundo (subida).

Después del aire envenenado por la putrefacción, sigue una frase clave porque sintetiza el sentido contrapuntístico. La crítica suele destacarla sin verle su proyección fundamental:

El camino subía y bajaba: "Sube o baja según se va o se viene. Para el que va, sube; para el que viene, baja" (id.; las cursivas son del original).

Apenas transcurre la primera hoja de lectura, estamos ubicados en el lugar, conocemos el motivo, el tiempo y el sentido del devenir. Un devenir que se define por la acción conjunta de subir y bajar. Será la acción del sujeto la que seleccione una u otra alternativa, criterio que es importante para el sentido de la historia que muestra la novela.

Más adelante sabremos que además la frase ofrece otra clave de interpretación: integra, complementándolos, el enunciado de Juan Preciado y el de Doloritas su madre (lo que delata el uso de la cursiva, característico del enunciado de Doloritas recordado por Juan Preciado). Es pues el binomio de relación real que el texto privilegia desde el comienzo, relativo a la tríada familiar. De la relación padre-hijo hablan los otros: "me dijeron que acá vivía mi padre, un tal Pedro Páramo"' (p. 7). Para Juan es claro que los "sueños" y las "ilusiones" que lo impulsan a venir identifican a Pedro Páramo con la "esperanza", pero no objetivan la relación:

de este modo se me fue formando un mundo alrededor de la esperanza que era aquel señor llamado Pedro Páramo, el marido de mi madre (id.).

Desde un punto de vista estructural, la novela sigue de cerca, en sus dos primeras páginas, el modelo tradicional del género, el cual exige un comienzo que muestre las claves principales de la obra. También, hecho frecuente en un narrador personaje de primera persona, el protagonista habla de sus padres.

Aunque no me detendré mucho en aspectos de este tipo, si bien es clara la ruptura que supone la novela respecto a modelos anteriores (en su fragmentación y el tratamiento temporal y es- 
pacial), ello no implica la supresión total de éstos, como hemos observado. Pedro Páramo asume los modelos, los transforma o transgrede. En el crisol de múltiples tendencias se conforma su modernidad y su historia. Estamos, sin lugar a dudas, ante un clásico contemporáneo.

\section{2. "El llano en llamas" y "Pedro Páramo". Homología estructural}

Al comienzo de este trabajo, notamos que los cuentos inciden en Pedro Páramo en un sentido amplio y diverso. En buena medida el autor experimenta en ellos lo que pretende llevar a la novela después, o cataliza modalidades y aspectos del proceso de la escritura de Pedro Páramo (p. ej. "Luvina")13. Existe además un cierto paralelismo estructural entre ambos libros.

El llano en llamas consta de quince cuentos. Ocupa el lugar central del libro "El llano en llamas", que es también su centro de significación. Como vimos antes, en él se conjuga el proceso histórico vuelto discurso (el período revolucionario) con los efectos de ese proceso en términos de la tríada familiar. Se revela cómo el crimen entre hermanos ("la marca de Caín") condena al pueblo al éxodo interminable. No obstante, hay un signo claro de proyección al futuro, pues se logra la transformación del padre, se restablece la tríada familiar y queda el hijo (criado por la madre, en ausencia del padre, aunque se le parece).

En los siete cuentos que anteceden, hemos presenciado la orfandad, los problemas del reparto de tierras y de la población campesina diezmada, el crimen individual contra otros hombres y la venganza.

Inmediatamente antes de "El llano en llamas" aparece "Talpa" que narra la relación incestuosa y el crimen camítico en un contexto de mercantilización de los valores religiosos y de la pérdida de relaciones sociales solidarias. Se marca así la génesis del estallido histórico.

${ }^{13}$ Rulfo comenta esta relación entre los cuentos y la novela: "Pedro Páramo lo tenía en la cabeza desde hacía muchos años. La tenía escrita en la cabeza, pero no encontraba la forma. Los cuentos me sirvieron de ejercicio" (ARmando Ponce, "Juan Rulfo", en Proceso, núm. 204, 29 de septiembre de 1980, p. 42). Sobre la relación específica de Pedro Páramo con "Luvina" dice: "Sí, «Luvina» creo que es el vínculo, el nexo [...] esa atmósfera me dio, poco a poco, casi con exactitud, el ambiente en que se iba a desarrollar la novela", en Sábado, suplemento cultural de Uno más Uno, núm. 98, 29 de septiembre de 1979 , p. 4. 
Después de "El llano en llamas", en los siete cuentos que siguen, aparece "¡Díles que no me maten!”, donde se plantea el problema de la muerte del padre y de la venganza de su muerte (como en Pedro Páramo). Ambos mundos (el de la esfera militar - ambigua por su orfandad, pero con un recuerdo positivo del padre - y el campesino - con la familia rota por la ausencia del padre) están condenados a escindirse debido a la culpa del crimen acaecido treinta años antes, a causa de la injusta repartición de la tierra. Durante ese tiempo el hombre huye continuamente $y$, en cierto modo, paga su crimen. Pero para la ley de signo patriarcal, sólo queda como destino la muerte del padre, al mismo tiempo culpable y víctima. "Luvina" sintetiza la caída y deterioro último del mundo patriarcal, en contrapunto con los signos de vida de otra generación, como ya señalé. Estamos justo en el ámbito del sentido de Pedro Páramo.

Los últimos cuentos tratan, en general, del destino de los hijos (del futuro, aspecto central de la novela). Todos censuran fuertemente la relación padre-hijo, cuyo fracaso se objetiva en la muerte del hijo en "No oyes ladrar los perros". Un hijo que recuerda la conducta licenciosa de Miguel Páramo y que es la proyección de su padre (como lo sugiere la figura conjunta de ambos en el cuento, que no logra la fusión de los contrarios indicativa de una regeneración).

En 'Paso del Norte"' el padre se va y provoca la escisión familiar. Se plantea el crimen y los problemas del bracerismo como vías sin solución, pero quedan los hijos como un posible futuro. Finalmente, en el ambiente paródico de "Anacleto Morones" se abre también un interrogante sobre el hijo no nacido aún, que se pierde con la madre. Sin embargo, dada la lógica textual, el hijo incestuoso de Anacleto podría implicar la proyección del mundo del padre en el futuro.

Es claro entonces que el centro del libro - el mundo sintetizado de la caída y la posibilidad de resurrección- podría expandirse a "Talpa” y a “ ¡Díles que no me maten!', si bien el centro primordial es "El llano en llamas" ("Luvina"' y los que siguen corresponden a los efectos de la caída, en contrapunto con los signos renovadores de afuera).

Esta idea del centro como el lugar donde se define el sentido es decisiva en el mundo de Rulfo. Es, como ocurre en El llano en llamas, el espacio que determina la organización textual general.

Si en El llano en llamas se define en el escenario histórico central la culpa individual y colectiva, en Pedro Páramo, destruido el 
mundo patriarcal, se define el sentido de la historia en el espacio central, sagrado y simbólico de las transformaciones. Se trata de objetivar en los símbolos el cambio cualitativo necesario que deberá surgir del hombre mismo.

La novela crea también su centro. El libro está dividido en 70 fragmentos $^{14}$. Entre el 30 y el 36 se da el rito de pasaje de un mundo a otro. Corresponden estos fragmentos a la entrada de Juan Preciado al espacio sagrado de abajo. Al mismo tiempo, de esos siete fragmentos se privilegia el del medio (el 33), con una connotación cristiana evidente que explicaré más adelante al hablar de los fragmentos y las partes de la novela. Destaca también el fragmento 35, que es el medio aritmético de toda la novela.

\section{Dos narradores principales; dos ópticas}

De los cuentos de El llano en llamas se desprende la importancia que tiene el hecho de tener voz o no tenerla en el mundo rulfiano. Se destaca el oído (también la vista, en segundo orden) y es por eso muy significativo que el hombre pierda incluso el deseo de hablar, conforme se acentúa el ejercicio arbitrario del poder sobre su vida. Sobran las palabras en un mundo donde la ley se ejerce al margen de la justicia (cf. "Macario" y "Nos han dado la tierra'”). Ser dueño de la palabra implica, pues, un poder sobre el mundo y la posibilidad de un acto liberador.

Pedro Páramo se distribuye en dos grandes enunciados principales, a cada uno de los cuales corresponde un narrador y un punto de vista dominante. El primero es el del hijo Juan Preciado, quien asume el discurso en primera persona, desde el comienzo de la novela, y domina durante todo el primer movimiento. A partir del fragmento 40 sólo aparece cuatro veces de manera significativa. El segundo narrador es la conciencia omnisciente del mundo de Pedro Páramo; domina en la segunda parte y aparece diez ve-

${ }^{14}$ Algunos críticos han señalado que existen variantes de una edición a otra en la división de las partes, sin añadir mucho más. En efecto, se registra una diferencia, por lo general, de uno o dos fragmentos, que obedece a una separación equivocada de algunos de éstos. Considero que la mejor edición es la que he utilizado en el trabajo (cf. nota 1). Imagino que, en parte, los errores se han debido a descuidos y al hecho de que hasta la edición de Bellas Artes de 1980 no se habían utilizado marcas gráficas específicas para separar unos fragmentos de otros. Conviene aclarar que las variantes de las ediciones publicadas no alteran significativamente la interpretación, pues los fragmentos que constituyen el "centro" del sentido se mantienen como tales. 
ees en la primera. Narra en tercera persona, y a veces cede la palabra a otro de los personajes de su mundo. Su punto de vista omnisciente oscila con el de primera persona de sus interlocutores; como un lente fotográfico que va del close up a una visión más distanciada de los hechos. Esto garantiza la credibilidad de lo narrado con mayor fuerza. Al mismo tiempo, es la voz que corresponde a la no-persona. Implica una pérdida de poder del padre, $\mathrm{Pe}$ dro Páramo, centro de atención de este segundo enunciado.

Este paso del punto de vista dominante de la tercera persona a un punto de vista de primera persona en el segundo movimiento, se reproduce entre los fragmentos, cuando hay cambio del narrador principal. El efecto refuerza el ritmo ascendente y descendente característico de la novela.

Sin embargo, los enunciados nunca se confunden, ni coinciden en un mismo fragmento. Ante el lector se alternan frecuentemente, lo cual produce un efecto de simultaneidad temporal y espacial que entrevera ambas historias al desarrollarse éstas en el texto. No obstante, sabemos que para los entes de ficción son partes incomunicadas. La comunicación se dará, por excepción altamente significativa, en el enunciado del hijo, en el presente y entre los muertos, que es el mundo de la esperanza y del posible nacimiento del hombre nuevo. Por eso morir es "acortar veredas" (Eduviges, p. 16) y para los de "Luvina", "la muerte [...] es una esperanza"' (p. 119).

Un detalle adicional: la novela se inicia con la llegada de Juan Preciado a Comala: "Vine a Comala [...]". Es decir, con Juan Preciado vivo, dueño de su acción y de la voz. Sólo sabemos que ha muerto en el fragmento 37, inmediatamente después de los fragmentos centrales (30-36) que narran el sacrificio de Juan Preciado y el rito de pasaje a un nuevo orden en el mundo bajo el signo del hijo, quien es enviado para sustituir a la madre (mundo lunar de las transformaciones). Lo que equivale a decir que ha muerto para vivir y dar la vida. La novela concluye con la muerte definitiva (sin posibilidad de regeneración) del mundo opresor de Pedro Páramo. La piedra invierte su fuerza monolítica. El hombre desaparece sin voz (sin poder) y sin cuerpo (sin placer); queda sólo una súplica que no se manifiesta, como si se le negara aun el murmullo característico de las ánimas y de los vivos suplicantes en Pedro Páramo: "cayó, suplicando por dentro; pero sin decir una sola palabra. Dio un golpe seco contra la tierra y se fue desmoronando como si fuera un montón de piedras"' (p. 159). 
4. Los fragmentos y las partes

Los dos enunciados principales que organizan el texto le dan también su fluidez entrecortada; se entreveran y marcan dos unidades, definidas por la preeminencia de uno de los enunciados sobre el otro.

Estas unidades corresponden a los dos movimientos de la imaginación que constituyen la novela. Uno ascendente, con una clara perspectiva de profundidad ética (el del hijo, Juan Preciado). El otro descendente (el del padre, Pedro Páramo), de muerte sin esperanza de resurrección (muerte que ya temía Macario, el primer gran huérfano de El llano en llamas) que se da en las sucesivas caídas y muertes de Pedro Páramo, contrapunteadas por el anhelo del ideal (su deseo de Susana San Juan). La ondulación de la caída lleva a la experiencia de la "caída infinita"'15.

En la organización textual estos dos grandes movimientos dividen en dos el texto; forman un eje vertical con un núcleo fundador trino, entre ambos (fragmentos 37-39), que sintetiza el sentido, equilibra la novela y cancela la posibilidad del vacío de la escisión (punto sobre el que volveré después). El primero se da del fragmento 1 al 36. El segundo del fragmento 40 al 70.

Dentro del primer movimiento ocurre la transformación de Juan Preciado entre los fragmentos 30-36, de orden trino también, que tienen como centro el fragmento cristológico 33. En el segundo se destacan los fragmentos 48-51 y 62-65 en los cuales ocurre la muerte y transfiguración última de Susana San Juan.

¿Cómo se organizan los fragmentos del primer movimiento? El mundo de Juan Preciado. El quinario armónico (fragmentos 1-5)

Al iniciar este trabajo, comenté la extraordinaria economía textual del comienzo de la novela, y señalé algunos aspectos que allí se destacan. Basta ahora recordar las relaciones privilegiadas: la de madre-hijo que se presenta como la "real" y la de padre-hijo inexistente y, por lo tanto, acicate de la esperanza. También aparece la unión no incestuosa de los hermanos en el campo iniciático (se topan en Los Encuentros, donde Juan esperó la llegada de Abundio).

El ambiente se satura de los signos maternos: la voz de la madre viva actualizada en el recuerdo, ordenando el destino ("su voz

${ }^{15}$ Cf. G. BaChELARD, "Nietzsche y el psiquismo ascensional", en op. cit., pp. $122-123$ y $199-200$. 
era secreta, casi apagada, como si hablara consigmo misma... Mi madre', p. 8. Los hijos (Abundio y Juan) llevan el apellido de la madre ${ }^{16}$. El segundo encuentro de Juan es con Eduviges, iniciadora ambigua en el camino de la muerte; mujer que ya antes sustituyó a su madre y que la conocía desde joven.

Es interesante destacar la primera caracterización que recibe Juan Preciado de su padre, en boca de su medio hermano: "Un rencor vivo" (p. 10) que "murió hace muchos años" (p. 12). La ambivalencia aparente se resuelve pronto. Lo que resta de Pedro Páramo al empezar la novela es ese rencor que vive en los demás hacia él y que se manifiesta, por ejemplo, en el gesto de Abundio: "dio un pajuelazo contra los burros, sin necesidad" (id.). También con la alusión al rencor se anima el retrato de la madre de Juan Preciado: "Sentí el retrato de mi madre guardado en la bolsa de la camisa, calentándome el corazón, como si ella también sudara..." (id.). Ya desde antes sabemos de su rencor: "El olvido en que nos tuvo, mi hijo, cóbraselo caro"' (p. 7).

Juan Preciado sigue el camino trazado por su madre, pero antes lo asume por sí mismo y espera con ilusión lo que va a acontecer (¿inducido por los "sueños" y las "ilusiones" de lo alto?, id.). Para que cumpla su destino la madre ha sabido edificar en su sensibilidad la imagen paradisíaca de la tierra prometida, su tierra. Es este discurso el que establece el contrapunto ascendente contra la realidad de la caída del tiempo actual ("¿Y por qué se ve esto tan triste? - Son los tiempos, señor', p. 8).

El hijo arriero muestra la tierra del padre y del padrino (dueño sin objeto de la carne y del espíritu): "nuestras madres nos malparieron en un petate aunque éramos hijos de Pedro Páramo. Y lo más chistoso es que él nos llevó a bautizar'” (p. 11). El latifundio está signado por los símbolos de lo bajo y perverso: una "loma que parece vejiga de puerco", símbolo de los deseos impuros, de la transformación de lo superior en inferior y del abismamiento amoral en lo perverso ${ }^{17}$, en contraste con el nombre de Media Luna que indica el mundo superior en el ámbito pa-

${ }^{16} \mathrm{El}$ texto oculta el de Abundio hasta el final, cuando va a dar muerte a Pedro Páramo. Pero el nombre ya lo identifica con el mundo materno desbordado ('fuera del agua', 'desbordarse el agua'). Cf. Gutierre Tibón, Diccionario etimológico comparado de nombres propios de persona, FCE, México, 1986, s.v. Abundio.

17 J.E. Cirlot, op. cit., s.v. cerdo. 
triarcal, representado por la luna nueva ${ }^{18}$ (inversión de valores característica del mundo de Pedro Páramo).

El fragmento 3, centro de esta primera parte, como todos los centros en la obra, conjuga los contrarios. El ayer vital del atardecer en Sayula con el ahora devastado de Comala, "pueblo sin ruidos", en ruina, lleno de ecos (es decir, vacío de sonido propio).

La imagen para caracterizar el espacio vital, abierto al futuro, es una ampliación de la que aparece en "Luvina" con la misma función:

Era la hora en que los niños juegan en las calles de todos los pueblos, llenando con sus gritos la tarde. Cuando aún las paredes negras reflejan la luz amarilla del sol.

[...] Y había visto también el vuelo de las palomas rompiendo el aire quieto, sacudiendo sus alas como si se desprendieran del día. Volaban y caían sobre los tejados, mientras los gritos de los niños revoloteaban y parecían teñirse de azul en el cielo del atardecer (p. 12).

La presencia del espacio vital, aéreo y alado, y la voz de la madre aún más clara en su interior, es suficiente para no debilitar la esperanza. Juan Preciado siente lo que la vista y el oído le niegan: "Y aunque no había niños jugando, ni palomas, ni tejados azules, sentí que el pueblo vivia" (p. 13). Es una fe que lo fortalece para cumplir su destino. El fragmento siguiente recuerda lo dicho por Abundio al despedirse. Sitúa la casa del arriero en un espacio alto " "más allá, donde se ve la trabazón de los cerros. Allá tengo mi casa. Si usted quiere venir, será bienvenido" (p. 14).

Abundio dirige a Juan Preciado a la casa de Eduviges Dyada. Ha sido casa de paso de los que se van (de los que suben); ahora lo es de los que llegan para bajar (y poder subir después).

$\mathrm{El}$ arriero de Los Encuentros queda como un enigma que se reabre en el fragmento 9. Eduviges se identifica con Doloritas, la madre de Juan Preciado y tiene una triple función: 1) Prepara a Juan para la muerte que "acorta veredas". Como el soldado romano - su nombre equivale a 'la que lucha en las batallas'cree en la cicuta, ya que en el mundo de Comala morir es librar una batalla liberadora. 2) Es enviada de la madre para guiarlo en el camino. Después pretende alcanzarla a ella en "alguno de los caminos de la eternidad" (p. 17). 3) Le revela a Juan Preciado que él pudo ser su hijo.

${ }^{18}$ Cf. Mircea Eliade, "Metafísica lunar", en Tratado de historia de las religiones, pref. de Georges Dumézil, Era, México, 1972, p. 176. 
Juan Preciado es dócil al llamado; se sumerge en ese mundo ("Me sentí en un mundo lejano y me dejé arrastrar", id.). Queda interrumpido su diálogo con Eduviges, que se reanudará en el fragmento 9 .

\section{Fragmentos 6-8}

Mientras Juan Preciado baja al submundo, pasamos al tiempo alto, paradisíaco, de la niñez de Pedro Páramo. Ha pasado la Revolución ("Ya se había ido la tormenta", id.) y hay todavía una esperanza en la tierra.

Este núcleo se inicia con el efecto del agua sobre la arena. Agua que cae del techo y no del cielo. Es un mundo germinal, materno y femenino (humedad, plantas, tierra) en armonía y unión con los signos vitales y solares: "Al recorrerse las nubes, el sol sacaba luz a las piedras, irisaba todo de colores, se bebía el agua de la tierra, jugaba con el aire dándole brillo a las hojas con que jugaba el aire"' (p. 18).

Esa conjunción equilibrada es breve y da paso a un contraste tajante. Sentado en el excusado, Pedro evoca a Susana San Juan, el ideal inaccesible: "'Escondida en la inmensidad de Dios, detrás de su Divina Providencia, donde yo no puedo alcanzarte ni verte y adonde no llegan mis palabras"' (p. 19). Hemos pasado de lo más bajo a lo más alto, los dos extremos de la obra de transmutación. El proceso ha sido radical. Es innegable el carácter melibeico de ese amor sustituto de Dios, condenado por imposible.

Pedro, sin embargo, queda atado a un tiempo anterior de la infancia donde sí se dio la unión paradisíaca, en consonancia con la naturaleza (p. 18). Si la felicidad de la vida amorosa no se logra, Pedro Páramo escoge desde la niñez la mercantilización de la vida como satisfactor. De las heces (lo bajo que posibilita lo alto: el oro alquímico; la felicidad de la vida corporal y lo valioso en psicoanálisis), se pasará a la ganancia del oro entendido como poder adquisitivo material y no como lo más alto: "Encontró un peso. Dejó el veinte y agarró el peso. "Ahora me sobrará dinero para lo que se ofrezca», pensó" (p. 21).

Se ha gestado la personalidad escindida de Pedro Páramo, que los sucesos próximos se encargarán de reafirmar. Personalidad escindida entre el amor ideal y el quehacer histórico de dominio, sin que se dé el punto de equilibrio, cuya posibilidad de realización parece cancelada (muerte del abuelo, madre "despedazada" por el dolor, aplastada del techo, abajo). 
Fragmento 9. Sentido armónico de Abundio

En el presente, por contraste, se completa la imagen de Abundio: situado en lo bajo de la escala social, su ritmo dominante es ascendente. Querido por todos, fue el correo, el nexo entre este mundo y el otro lado del mundo, antes de "su desgracia" (ensordecimiento accidental simbólico porque no sale de su interior, sino que le viene de la circunstancia histórica que vive). En el presente de la escritura Abundio vive en lo alto. ¿Es mediador para la conjunción necesaria del cielo con la tierra? Así parece sugerirlo el diálogo entre Eduviges y Juan Preciado. Ella relata que antes quedó sordo y dejó de hablar. Juan insiste en su capacidad auditiva y Eduviges no parece tener seguridad de lo que ha afirmado:

-Éste de que le hablo oía bien.

- No debe ser él. Además, Abundio ya murió. Debe haber muerto seguramente. ¿Te das cuenta? Así que no puede ser él.

-Estoy de acuerdo con usted (p. 23).

Lo que se revela es que, como en el Evangelio, para lograr el sentido es necesario "oír". Sólo quien oye puede hablar. Si bien Juan Preciado narra su historia en primera persona, su narración nos lo mostrará más atento a oír que a hablar. Es su ritual de aprendizaje. Conforme oye, actúa.

Juan Preciado conoce ya la función de Abundio. Conocerá también, en este fragmento, la sustitución de la madre por Eduviges la noche de la boda con Pedro Páramo. La orden de la madre es análoga a la que da a Juan Preciado: "-Ve tú en mi lugar, me decía"; con ella logra cumplir un objetivo: ¿determinar el tiempo del nacimiento de Juan Preciado? ("Al año siguiente naciste tú; pero no de mí [...]", dice Eduviges, p. 26). No hay duda que Juan Preciado, como su nombre lo indica, es el elegido; el preferido "lunar" para el cambio, como se verá después.

Un saber decisivo es que Juan Preciado comprenderá el rencor de la madre hacia Pedro Páramo, y por qué se aleja de él llevándose al hijo. Este saber socava la posibilidad de un encuentro a distancia con la imagen paterna que debe desaparecer en el hijo ¿para que el pueblo sea el " paraíso recuperado"'? De ahí el contrapunto entre el lugar anhelado y posible y el páramo de la cotidianidad esclavizante de la madre en su vida con Pedro:

“. . Llanuras verdes. Ver subir y bajar el horizonte con el viento que mueve las espigas, el rizar de la tarde con una lluvia de triples rizos. El color 
de la tierra, el olor de la alfalfa y del pan. Un pueblo que huele a miel derramada...'

$[\ldots]$

“Ella siempre odió a Pedro Páramo. «iDoloritas! ¿Ya ordenó que me preparen el desayuno?»Y tu madre se levantaba antes del amanecer $[\ldots]$.

“ ¿Cuántas veces oyó tu madre aquel llamado? "Doña Doloritas, esto está frío. Esto no sirve». ¿Cuántas veces? Y aunque estaba acostumbrada a pasar lo peor, sus ojos humildes se endurecieron"' (id.).

Nosotros lectores conocemos además la pérdida del paraíso muy temprano en la vida de Pedro Páramo (saber que no conviene a Juan Preciado para la firmeza necesaria a su destino liberador). Este saber del lector se precisa en el fragmento siguiente.

\section{Fragmento 10. Mundo fragmentado de Pedro Páramo}

Pedro Páramo excepcionalmente asume la primera persona en todo el fragmento que revela el hecho desencadenante de la gran caída: la partida de Susana San Juan y su "odio" hacia el pueblo de Comala (p. 28).

Pedro Páramo, sin alma, sin centro, se inicia como el gran negador de la vida y de su modelo evangélico, Pedro, a quien sigue fragmentariamente también (en el gesto externo de la negación, y no en su sentido integral). Lo primero es su negación a "resignarse". Su arbitraria ¿trágica? rebeldía contra la vida. La premonición de la abuela confirma el destino abyecto del ¿preadolescente?: "Siento que te va a ir mal, Pedro Páramo" al finalizar el fragmento (p. 29).

Fragmentos 11-15. Orfandad de Pedro Páramo; muerte de Miguel Páramo y crimen contra el pueblo de Dios (el Éxodo)

Del quinario armónico inicial de Juan Preciado (lo alto) pasamos al quinario sin centro, de orfandad y muerte, de Pedro Páramo (lo bajo). En este modelo de sentido se conjugan los dos enunciados principales. El centro (fragmento 13) va a la raíz.

La muerte de Miguel Páramo es ejemplar para Juan Preciado (fragmentos 11 y 12), ya que en el mundo de los hijos Miguel pretendió sobrepasar, acortando los tiempos, los antivalores del mundo paterno (p. 31). El modelo superior del caballero que subyace en su figura está negado totalmente con su vida. Es el antihéroe (la 
negación de la función heroica que sería propia del hijo en un mundo patriarcal orientado hacia la vida, lo alto). Es un saber, pues, que templa el espíritu de Juan Preciado para cumplir su objetivo.

$\mathrm{Al}$ mismo tiempo, en el segundo enunciado - dirigido al lector - su muerte corona la imposibilidad de futuro del mundo patriarcal que claramente representa en su valor invertido. Se sugiere que su crimen es imperdonable, ya que vulnera el principio rector de la Iglesia en tanto "pueblo de Dios". Mata al padre y hermano y viola a la mujer que la representa, si bien ella no está totalmente exenta de culpa pues deja hacer.

El texto, como en los enunciados de la madre, reafirma (esta vez para el lector) la posibilidad de salvación, y condena a Miguel Páramo (véase el comienzo del fragmento 14). Es, tal vez por el detalle del entrecomillado sin cursivas, la voz del narrador omnisciente, quien se declara parte del "nosotros" (iel autor?):

Hay aire y sol, hay nubes. Allá arriba un cielo azul y detrás de él tal vez haya canciones; tal vez mejores voces... Hay esperanza, en suma. Hay esperanza para nosotros, contra nuestro pesar.

Pero no para ti, Miguel Páramo, que has muerto sin perdón y no alcanzarás ninguna gracia (p. 34).

Esta realidad cuestiona gravemente al guía espiritual de ese pueblo: el.padre Rentería. Él está llamado a intensificar los vínculos fraternos que religan con Dios Padre. Conocemos su conflicto entre la práctica de su ministerio, su naturaleza humana y su fe y misión cristianas. Como hombre condena a Miguel Páramo; como sacerdote deja en Dios la decisión última y acepta en su interior, no sin dolor, la posibilidad de salvación (fin del fragmento 14 y del 15).

Los efectos sociales (disgregación del "pueblo de Dios") e históricos (pérdida del futuro) remiten al centro del núcleo de sentido (fragmento 13). Allí se muestra la muerte consecutiva del padre y de la madre de Pedro Páramo. A esta última la sabíamos ya vulnerada ("despedazada"; sin centro, debido a la muerte del padre). La orfandad en el nivel simbólico implica la pérdida de la ley moral, de la raíz y del amor nutriente y protector o, más bien, el vacío de la deseada unión de los contrarios, generadora de la vida $^{19}$.

19 Estamos lejos del drama del niño abandonado que "se ve compensado por la grandeza mítica del 'huérfano', del niño primordial en su absoluta e 
Fragmentos 16-17. El juicio popular y la culpa

La muerte de Miguel Páramo permite un indicio de subversión popular. Como ante el gobierno en "Luvina", el pueblo ríe burlonamente y emite un juicio contundente: "se murió muy a tiempo". Se teme todavía, sin embargo, a la presencia del padre, Pedro Páramo.

El padre Rentería asume su culpa, condicionado también por el temor: ha mercantilizado su iglesia; ha cambiado, como Pilatos, su servicio de la misa del perdón por unas monedas. Ha descuidado su función pastoral por "el temor de ofender a quienes me sostienen [...]. Ellos me dan mi mantenimiento. De los pobres no consigo nada [...]. Así ha sido hasta ahora. Y éstas son las consecuencias. Mi culpa"' (p. 40).

Este temor del "pueblo de Dios" hacia el poder absoluto, ligado a los efectos opresores de la estructura económica, justifica la segunda parte de la novela: es necesario ver morir con todas sus contradicciones (Pedro Páramo es opresor y víctima) a la esfera del poder absoluto.

\section{Fragmento 18}

El aprendizaje de Juan Preciado se acerca a su fin. Educado a "sentir", más que a razonar, le basta el pasaje metafórico del grito del ahorcado ${ }^{20}$. Éste grita su reclamo y su impotencia, y el grito adquiere dimensiones de hondura incalculable. Es la voz colectiva del pueblo sacrificado - sin objetivo cierto - irónicamente detenida entre el cielo y la tierra, reclamando justicia. Ineludible es la asociación, en el plano social concreto, con los ahorcados que pueblan la novela de la revolución, se marcan en El llano en llamas y condicionan para siempre la imaginación de Rulfo:

Era un grito arrastrado como el alarido de algún borracho: “ ¡Ay vida, no me mereces!"

$$
[\cdots]
$$

invulnerable soledad cósmica, en su unicidad. La aparición de semejante 'niño' coincide con un momento auroral: creación del cosmos, creación de un mundo nuevo, una nueva época histórica [...], una 'vida nueva', en cualquier nivel de la realidad"' (Mircea Eliade, op. cit., p. 230).

${ }^{20}$ Cf. J.E. Cirlot, op. cit., s.v. ahorcado. 
No, no era posible calcular la hondura del silencio que produjo aquel grito. Como si la tierra se hubiera vaciado de su aire. Ningún sonido; ni el del resuello, ni el del latir del corazón; como si se detuviera el mismo ruido de la conciencia. Y cuando terminó la pausa [...] retornó el grito y se siguió oyendo por un largo rato: "¡Déjenme aunque sea el derecho de pataleo que tienen los ahorcados!" (p. 43).

Es una imagen sonora que condensa toda la fuerza de ese mundo llamado a ser liberado, como en torno a un grito se ordenó en el pasado el mundo de Pedro Páramo (véase el segundo movimiento). Sugiere también que Juan Preciado deberá liberar el alma de ese mundo, aprisionada en la roca sorda de la materia (reminiscencia clara del mito de Andrómeda, asociado en la novela a Susana San Juan y a su padre, dueños de la mina La Andrómeda, y a la mujer del submundo, cf. infra).

El grito precede a la aparición de Damiana, madre y abuela de la Media Luna, cuya función se aclarará en el segundo movimiento. Ahora su actuación es ambigua: acoge y tienta a Juan, invitándolo a dormir a la Media Luna. Parece viva. Recuerda que ha sido su primera nana y Juan, a su vez, la reconoce porque su madre le había hablado de ella. Tal vez sólo es un paliativo para el desasosiego causado por el grito y la inminencia de lo que va a ocurrir. Lo que es indudable es que ella, como Eduviges, representa el cordón materno que lo guía.

Fragmentos 19-24. La pérdida absoluta de los límites. Inversión de lo alto

Muerto el padre de Pedro Páramo, queda su capataz Fulgor Sedano, quien representa inicialmente la antigua ley opresora. Será, sin embargo, el ejecutor de la nueva ley del hijo (Pedro: la negación de Cristo): ley de la muerte, del despojo, de la mercantilización de los valores más estimados (la relación con la mujer, la familia, la iglesia sacramental y la iglesia "pueblo de Dios", la propiedad justa de la tierra, su sentido vital).

Sabemos que Pedro Páramo está condenado porque su negación ha rebasado con creces el límite del padre ("La ley [.. . ] la vamos a hacer nosotros [...]. Lucas Páramo ya murió", p. 53). Por eso ha muerto su futuro, cosa que ya sabemos desde que murió Miguel Páramo. La admiración y sumisión de Fulgor ante ese poder opresor le hace negar también su naturaleza positiva ("resplandor, brillo propio"). Más bien encarna la dimensión simbó- 
lica de su nombre: "símbolo de la fuerza de lo indiferenciado, de la disolución" según Évola21.

El crimen se entrevera y se suma al casamiento por interés de Pedro Páramo con Dolores Preciado, para "pagar' la antigua deuda de los Páramo a las Preciado. No es extraño que de lo tenido en menos surja la fuerza de la renovación que crece oculta y seguramente (la locura de la Cruz).

Pedro Páramo determina su casamiento con Dolores; la orden del crimen moral la ejecuta Fulgor; también el despojo. En el sentido de lo alto la mujer se asocia simbólicamente con la tierra por su fuerza generadora de nueva vida. Pedro Páramo - y en consecuencia Fulgor - utiliza a la mujer para acaparar la tierra (así Fulgor: " "Vente para acá, tierrita de Enmedio". La veía venir [...]. Lo que significa una mujer después de todo", p. 50).

Rebasados los límites (Pedro Páramo: “No te preocupen los lienzos. No habrá lienzos. La tierra no tiene divisiones', p. 49, mercantilización del sentido simbólico de la madre tierra) se fortalecen los síntomas de la necesidad de la subversión de ese mundo. Dolores Preciado, dueña del rancho de Enmedio, parece cumplir un destino superior de mediación, como el nombre de su tierra lo indica. Con ella, la mujer legítima, entra de lleno el mundo de la madre en la esterilidad de la Media Luna. Es evidente que es mujer regida por el destino lunar (es "la luna" de su menstruación la que interviene la noche de la boda y crea la distancia inicial en el origen mismo de la relación $)^{22}$.

La naturaleza indica la escisión de cielo y tierra. Arriba domina el mundo alado; abajo el aire se vuelve agresivo, caluroso: " $\mathrm{El}$ cielo era todavía azul. Había pocas nubes. El aire soplaba allá arriba, aunque aquí abajo se convertía en calor' (pp. 53-54).

${ }^{21}$ Cit. en ibid., s.v. fulgor.

${ }^{22}$ La gestación de Juan Preciado está envuelta en algo de misterio. En la hierofanía de la tierra "los niños no son concebidos por el padre, sino que en un [estadio] más o menos adelantado de su desarrollo, vienen a ocupar un lugar en el vientre materno después de un contacto entre la mujer y un objeto o un animal del medio [ambiente cósmico]" (M. EliADE, en "Estructura de las hierofanías telúricas", op. cit., p. 224). Conviene recordar la intervención de Inocencio Osorio, el Saltaperico que tenía el oficio de "provocador de sueños" quien prohíbe a la madre de Juan Preciado que se acueste con ningún hombre la noche de su boda (cfi. pp. 24-25). 
Fragmento 25. Ecos y rumores. El mundo vacio de su centro, como Pedro Páramo

Damiana, última guardiana del camino, previene a Juan Preciado de la conversión de Comala en un lugar de ecos y rumores de las ánimas que todavía rezan por el mundo: "Así que no te asustes si oyes ecos más recientes, Juan Preciado" (p. 55). Después desaparece y sólo queda el eco de la voz de Juan Preciado llamándola.

Fragmentos 26-29. Grupo cuaternario que anuncia la transformación de la tierra. La queja colectiva

Las voces del pueblo unen el pasado y el presente y los espacios. La conjunción sugiere que el mal social (ecos, murmullos, rumores, mugido) es el mismo antes y ahora.

Inicialmente (fragmento 26) Juan Preciado oye. Y oye, en primer término, la queja de las mujeres. Su temor a ser usadas en beneficio del poder absoluto. Como Agripina en "Luvina", son ellas las que se adelantan en el camino. Luego el narrador parece desaparecer para que no haya distancia entre el lector y la queja popular. Se oye entonces un diálogo que muestra la burla y el despojo de la tierra de los pequeños propietarios (¿medieros?). Siguen dos fragmentos, en uno de los cuales la soledad de la mujer (la imposibilidad de la pareja) se explica por la presencia del padre que se interpone en su vida (casarse implica la muerte del padre).

Sigue el fragmento 29. Breve pasaje sonoro que sintetiza la transformación gradual del ruido en canto. Canciones lejanas de penas de amor, que son tanto del hombre como de la mujer (por su tono melancólico, son propias de un tiempo lunar). Por eso el canto popular que se destaca en el texto parece estar en boca de hombre, pero la voz remite a la mujer. Una vez más estamos en el ámbito poético de Juan Preciado, en el cual las cosas nos llegan por la sensibilidad (mundo de tendencia femenina) más que por la conciencia (mundo de tendencia masculina). Son también expresiones sintéticas, nucleares.

Ruidos. Voces. Rumores. Canciones lejanas: 
En falsete. Como si fueran mujeres las que cantaran (p. 60; las cursivas son del original).

Las palabras vueltas canto, y canto popular, presagian el advenimiento de un nuevo mundo que supere el incesto de una sociedad vuelta hacia su pasado ideal, caduco históricamente.

\section{Fragmentos 30-36. Pasión, muerte y nuevo nacimiento de Juan Preciado}

En este septenario ${ }^{23}$ de fragmentos se produce la inversión necesaria para una transformación total del mundo presente en otro que se anhela (simbolizado por el deseo, la sed y la lluvia a través de toda la novela y en los cuentos).

El texto objetiva una nueva Pascua cristiana en el lenguaje simbólico universal, y en la cotidianidad de los elementos verbales y sensibles. Es la Pasión de Juan, el Preciado por Jesús. Junto con la madre Juan forma el nuevo binomio de este mundo que debe estar regido por el espíritu ("Al ver a su madre y a su lado al discípulo preferido, dijo Jesús: Mujer, ése es tu hijo. Y luego dijo al discípulo: Ésa es tu madre"' $)^{24}$.

Si los fragmentos simbolizan la nueva Semana Santa, el tiempo cronológico que transcurre es de tres días con sus noches ("el Mesías sufrirá, resucitará...' ') ${ }^{25}$.

Juan Preciado inicia el camino de su Pasión con una visión ejemplar que sintetiza en su efecto totalizador al mundo: el carro. Por tratarse de un mundo agrícola, y de su fundamento, son las carretas: "Vi pasar las carretas". Se contraponen de manera límite -en el máximo de tensión- la visión degradada, baja (el presente) y la visión alta (el pasado; el discurso de la madre en el recuerdo), en un ritmo en tres tiempos que privilegia el efecto de caída (bajo-alto-más bajo). De un lado los signos desvitalizados del comienzo y el cierre del pasaje (el movimiento pesado, los hombres como dormidos, la ausencia de frutos, el silencio, la noche, la sombra, el eco de las sombras); de otro, la exuberancia vital de

${ }^{23}$ El siete es "símbolo de la transformación y de la integración de la gama de jerarquías en su totalidad". Es, dice Hipócrates, "dispensador de la vida y la fuente de todos los cambios, pues incluso la luna cambia de fase cada siete días..." (C.. J.E. Cirlot, op. cit., s.v. septenario).

${ }^{24} \mathrm{Jn} 19,26-27$. Para todas las referencias a la Biblia utilizo la Nueva Biblia española (Edición latinoamericana), trad. dir. por Luis Alonso Schókel y Juan Mateos, eds., Cristiandad, Madrid, 1976.

${ }^{25} \mathrm{Lc} 24,46$. 
la madrugada que antecede a la primavera y ocupa el centro del pasaje:

Vi pasar las carretas. Los bueyes moviéndose despacio. El crujir de las piedras bajo las ruedas. Los hombres como si vinieran dormidos. "... Todas las madrugadas el pueblo tiembla con el paso de las carretas. Llegan de todas partes, copeteadas de salitre, de mazorcas, de yerba de pará. Rechinan sus ruedas haciendo vibrar las ventanas, despertando a la gente. Es la misma hora en que se abren los hornos y huele a pan recién horneado. $Y$ de pronto puede tronar el cielo. Caer la lluvia. Puede llegar la primavera'".

Carretas vacías, remoliendo el silencio de las calles. Perdiéndose en el oscuro camino de la noche. Y las sombras. El eco de las sombras (pp. 60-61; las cursivas son del original).

Inmediatamente después de esta última visión que sugiere el vacío más allá de las tinieblas, Juan Preciado - como Jesús en el monte de los Olivos ${ }^{26}$ - inicia su pasión con la tentación del regreso total (es decir, la anulación del Calvario): "Pensé regresar. Sentí allá arriba la huella por donde había venido, como una herida abierta entre la negrura de los cerros"' (p. 61).

Lo que ocurre, en cambio, sin transición, es la presencia de los hermanos incestuosos que esperan la llegada de su "hora" en ¿los Confines de la tierra? Se trata de una pareja adánica por todos los indicios.

En el fragmento 31 crecen los símbolos de la transformación. Las palabras dejan de ser "sentidas" y empiezan a recuperar su sonoridad. El lenguaje cobra su función distintiva. Por eso Juan Preciado destacará que siente y oye el mundo que lo rodea en el "albor del amanecer. Sentía la luz. Oía". Y lo que oye es lo que la mujer ve mientras él duerme:

Míralo cómo se mueve, como que no encuentra acomodo. Si se ofrece ya no puede con su alma $[\ldots]$.

- Se rebulle sobre sí mismo como un condenado [... . . Se restriega contra el suelo, retorciéndose. Babea. Ha de ser alguien que debe muchas muertes [...] (p. 64).

Más bien este revolcarse en el suelo supone que el contacto con la tierra favorece las posibilidades de "inversión" de un orden dado en su opuesto. Revolcarse es, según Cirlot $^{27}$, uno de

${ }^{26}$ Lc 22, 42-44.

${ }^{27}$ J.E. Cirlot, op. cit., s.v. revolcamiento. 
los actos sacrificiales que provocan o facilitan el "cambio de circunstancias y de corriente vital"'.

Con el sol de mediodía despierta Juan Preciado y pide orientación para salir del lugar. Ha pasado la prueba del enfrentamiento con todo lo negativo de este mundo. La pregunta provoca una descripción que revela el sentido mandálico ${ }^{28}$ del espacio. En tanto tal se puede precipitar en él un cambio espiritual o de cualquier orden. Constituye una imagen sintética del mundo que une los opuestos (Mircea Eliade) y que, a su vez, puede ser una proyección de la mente (Jung). Este espacio se debe interpretar dándole una importancia superior a lo más cercano al centro. ¿Cómo se configura el espacio a juzgar por el comentario textual?

¿Cómo se va uno de aquí?

- ¿Para dónde?

- Para donde sea.

- Hay multitud de caminos. Hay uno que va para Contla; otro que viene de allá. Otro más que enfila derecho a la sierra. Ése que se mira desde aquí, que no sé para dónde irá -y me señaló con sus dedos el hueco del tejado, allí donde el techo estaba roto-. Este otro de por acá, que pasa por la Media Luna. Y hay otro más que atraviesa toda la tierra y es el que va más lejos.

-Quizá por ése fue por donde vine.

- ¿Para dónde va?

- Va para Sayula (p. 65).

- La ordenación de estos espacios, a juzgar por las señales que se nos han dado en el texto, indica una figuración quinaria, armónica y trascendente, que parece ser la siguiente:

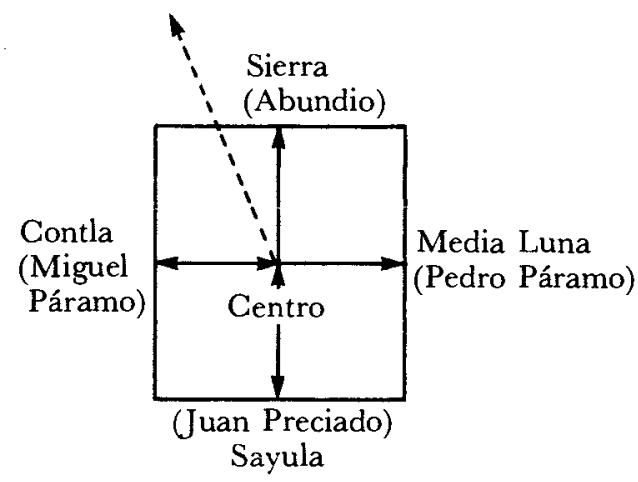

${ }^{28}$ Mandala es una palabra hindú que "significa círculo. Son una forma de yantra (instrumento, medio, emblema), diagramas geométricos rituales, al- 
De acuerdo a una lectura del símbolo como mandala, el camino más importante es el de la unión trascendente del hombre (estrella) con el cielo (luna) ${ }^{29}$, unión de los contrarios (hombre y mujer; verdad y sabiduría, respectivamente), sin que se confundan ambos entre sí. La línea vertical, en su orientación de arriba abajo representa el poder que desciende sobre la humanidad desde lo alto, y de abajo arriba el gran deseo del hombre de las cosas más altas, trascendentes. Finalmente, la acción del centro hará posible la transformación del mundo y de la naturaleza (el cuadrado externo signado por los cuatro elementos: aire, fuego, agua y tierra). Visto como una unidad, los triángulos dentro del cuadrado son el signo de la actividad debida al esfuerzo de la humanidad ${ }^{30}$.

Sin duda se nos ha dado la estructura figurativa clave que la

gunos de los cuales se hallan en concreta correspondencia con un atributo divino determinado o una forma de encantamiento (mantra) de la que vienen a ser la cristalización visual". Sirven "como instrumentos de contemplación y concentración (como ayuda para precipitar ciertos estados mentales y para ayudar al espíritu a dar ciertos avances en su evolución [...] desde el reino de las formas corpóreas a lo espiritual' '. El mandala, según Jung, es una imagen mental que puede elaborarse con la imaginación por alguien educado para ello. Son diferentes entre sí, pues proyectan el estado psíquico del autor en la idea tradicional del mandala. En resumen, es "una imagen sintética del dualismo [...] la exposición plástica, visual, de la lucha suprema entre el orden [...] y el anhelo final de unidad y retorno a la condensación original de lo inespacial e intemporal (al "centro" puro de todas las tradiciones) [ . . ]. La contraposición del círculo, el triángulo y el cuadrado (numéricamente, del uno y el diez, el tres, el cuatro y el siete) [desempeña] el papel fundamental de los mejores y más "clásicos» mandalas orientales. Aun cuando el mandala alude siempre a la idea de centro (y no lo representa visible, sino que lo sugiere por la concentricidad de las figuras), presenta también los obstáculos para su logro y asimilación. El mandala cumple de este modo la función de ayudar al ser humano y aglutinar lo disperso en torno a un eje (el Selbst de la terminología junguiana)". Desde un punto de vista psicológico, según Jung, nunca se podrá saber el significado último. El historiador de las religiones Mircea Eliade, en cambio, "busca principalmente en el mandala su objetividad [...] como una imago mundi antes que como una proyección de la mente, sin descartar, empero, el hecho". Dibujados sobre el suelo, tienen la función ritual de dar acceso al interior para identificarse con su historia ("sus etapas y zonas"). El mandala se lee del centro (lo superior o principal) a la periferia; véase J.E. Cirlot, s.v. mandala.

29 Cf. Mircea Eliade, op. cit., p. 105

${ }^{30}$ Cf. Rudolf Koch, Book of signs, Dover Publications, New York, 1930, pp. 1, 3-5 y 12 . 
novela propone. Después se hablará de la culpa colectiva que necesita del perdón para ganar la gracia, y con ella el descanso eterno.

Donis, el hermano-amante relacionado con el mito complejo de Adonis $^{31}$, anuncia su partida en la noche, y promete regresar en la mañana para encaminar a Juan Preciado. Se crean el tiempo y el espacio propicios al cambio. Nuevamente Juan expresa su deseo de regresarse ("Volver al lugar de donde vine", p. 69). Es la urgencia provocada por el temor humano que tienta siempre al elegido a la hora del sacrificio (como dos veces a Jesús, antes de su Pasión). Donis, el nuevo guía, le aconseja esperar (oír y esperar son las leyes que preparan el camino), ya que en la noche "todos los caminos están enmarañados de breñas" (id.).

La figuración del espacio centra todo el texto, como corresponde al momento cumbre de la historia relatada. Propone la abolición del retorno cíclico que, junto con el cambio y el ritmo, son las características por excelencia del tiempo lunar. "El mundo sublunar no es únicamente el de las transformaciones, sino también el de los sufrimientos de la "historia». Nada "eterno" puede suceder en esta zona sublunar cuya ley es el devenir"'32.

La novela muestra la posibilidad de trascender el devenir del eterno retorno y reintegrarse en la "unidad primordial" de "la polaridad"'. Mircea Eliade considera que esta reintegración, poco frecuente, colma una búsqueda universal del hombre, quien "desde que tomó conciencia de su situación en el cosmos [...] ha deseado, ha soñado y se ha esforzado en realizar de una mane-

${ }^{31}$ Una vez más, Rulfo crea un signo que revela la historia, a partir de la imaginación y con elementos de la mitología tradicional. Donis, como "señor' (Tammuz es su verdadero nombre), descubre y promueve "la unidad fundamental de vida-muerte, y [...] las esperanzas que el hombre tiene derecho a deducir de esa unidad fundamental en lo que se refiere a su propia vida después de la muerte (Mircea Eliade, op. cit., p. 381). Frazer señala que en la literatura religiosa de Babilonia, Tammuz es el joven esposo o amante de Istar, la diosa Gran Madre, personificación de las energías reproductivas de la naturaleza. Se creía que Tammuz moría todos los años, marchando de la tierra alegre al sombrío mundo subterráneo, y que todos los años su amante divina le buscaba hasta el 'país del cual no se vuelve, la casa de las tinieblas, donde el polvo cubre la puerta y el cerrojo'. Durante su ausencia, la pasión del amor desaparecía; los hombres y las bestias parecían olvidar la reproducción y toda la vida estaba amenazada de extinción; cf. JAMEs GEorge FraZER, La rama dorada. Magia y religión (1922), trad. Elizabeth y Tadeo Campuzano, FCE, México, 1944, p. 379. Es traducción de la versión inglesa, abreviada por el autor, de la obra original de 1890. Es evidente que esta versión -y no la clásica con Afrodita - es la que Rulfo tiene presente en la novela.

${ }^{32}$ Mircea Eliade, op. cit., pp. 175-176. 
ra concreta (es decir: por la religión y la magia al mismo tiempo) el rebasamiento de su condición humana" 33 .

En Pedro Páramo sólo un cambio cualitativo de esta índole garantiza la sustitución definitiva del mundo regido por el padre como poder arbitrario y absoluto. El acto conlleva la desaparición total de la condición histórica opresora y amenazante. Marca el nacimiento de un hombre nuevo enraizado en la historia como proceso trascendente de liberación.

Los fragmentos que siguen cumplen sucesivamente esa unidad primordial. La imagen clave, indicativa de ello, es La estrella junto a la luna, uno de los títulos probables de la novela que Rulfo sustituyó por el de Pedro Páramo ${ }^{34}$. El cambio hace menos obvia la referencia a ese motivo central del texto, que de hecho ha pasado prácticamente desapercibido para la crítica. Al mismo tiempo, destaca lo que el texto censura (el mundo de Pedro Páramo) y no su correlato positivo. Conforme lo indica el mandala espacial, la conjunción trascendente es el paso previo a la unidad de los contrarios y la posibilidad de un cambio en el mundo.

De aquí en adelante, es la naturaleza la que da la pauta: entre la noche y el día se produce una atmósfera más ligera que anuncia la transmutación. Inicia el fragmento 32 la imagen de la ventana (puente virtual entre lo alto y lo bajo), colocada justo en el lugar más alto del Centro. Como suele ocurrir en el ámbito de lo sagrado, de las ruinas (lo bajo) nace el vínculo con lo alto: "Por el techo abierto al cielo vi parvadas de tordos"'35.

Los pájaros, símbolo recurrente en Rulfo para marcar el cambio en la novela, son ahora tordos, aves conocidas en México como pájaros de la primavera ya que llegan en esa temporada y tienen

33 Ibid., p. 177.

${ }^{34}$ Otros títulos que Rulfo consideró apropiados para la novela fueron Los desiertos de la tierra (cercano al de Pedro Páramo) y Los murmullos (que remite a la culpa colectiva). Para el primero, véase su primer informe de trabajo como becario del Centro Mexicano de Escritores, 1953. Sobre los otros tres habla en una entrevista publicada por primera vez en Domingo (Puerto Rico), suplemento cultural de El nuevo día, 21 de abril de 1985, pp. 6 y 8: "El manuscrito se llamó sucesivamente Los murmullos y Una estrella junto a la luna. Al fin, en septiembre de 1954, fue entregado al Fondo de Cultura Económica, y se tituló Pedro Páramo".

35 Equivale al "agujero"' con el cual identifican el cenit algunas culturas orientales. Por éste "se verifica la transición y la trascendencia, es decir, el paso del mundo de la manifestación (espacial y temporal) al de la eternidad", J.E. Cirlot, op. cit., s.v. espacio. 
un canto muy melodioso ${ }^{36}$. También ve Juan Preciado otros signos iniciales de lo aéreo: "unas cuantas nubes ya desmenuzadas por el viento"' (p. 69). Este viento, que como siempre indica dinamismo, trae a la noche que es el tiempo propicio para el cambio (sólo de la noche podrá venir el día).

Primavera, alas, canto melodioso y, finalmente, la culminación alta de la imagen aérea que es el mundo celeste: "Después salió la estrella de la tarde, y más tarde la luna” (id.).

Juan Preciado queda prendido a la imagen, en un estado entre el miedo y la posesión:

Yo me quedé tieso, aguantando la respiración, buscando mirar hacia otra parte. Hasta que al fin logré torcer la cabeza y ver hacia allá, donde la estrella de la tarde se habia juntado con la luna (p. 70).

Una vez más, un cambio de óptica —de Juan Preciado a Donis - nos permite observar el temblor ${ }^{37}$ del primero hasta que cesa. Donis - el guía en el submundo- aconseja a la mujer que ambos dejen solo a Juan porque "Debe ser un místico" (id.). Es decir, alguien que busca la unión con Dios, en el cielo. (El encuentro fallido con el padre de la tierra, condenado a desaparecer por su adhesión al mundo materializado, se sustituye por la búsqueda de la unión trascendente con el espíritu).

Lo extraordinario desde el punto de vista del texto es que el cambio de óptica no implica un saber superior por parte de los personajes. El sentido está más allá de ellos, informándolos (el Centro es el lugar de la forma). Los hechos y asociaciones que aparentemente no rebasan los límites del personaje obligan a una lectura de desciframiento por parte del lector. ("Quien tenga oídos, que escuche". .) ${ }^{38}$ La escritura tiene la fuerza de la parábola evangélica, modelo subyacente que organiza el signo de la novela ${ }^{39}$.

${ }^{36}$ Cf. Roger Tory Peterson y Edward L. Chalif, A field guide to Mexican birds, Houghton Mifflin, Boston, 1980, p. 183.

${ }^{37} \mathrm{El}$ temblor indica el frío que se asocia a un valor más alto que el fuego. Sugiere la posibilidad de altura y de trascendencia de los contrarios (frío y fuego), tal como se dan en el camino de Juan Preciado; cf. G. Bachelard, op. cit., pp. 168-169; cit. además por J.E. Cirlot, op. cit., s.v. frío.

${ }^{38} \mathrm{Mt} 13,9-17$.

${ }^{39} \mathrm{Si}$ bien éste es un tema a desarrollar después —cuando vea la relación de la novela con otros textos y su proyección-, adelanto un çomentario. Considero que la forma de la parábola y su proyección trascendente en términos del sentido es la adecuada para el proyecto de escritura de Juan Rulfo. Se cum- 
Ya adelanté la asociación cristológica del fragmento 33. Se regresa la escritura al momento de la llegada, como si fuera necesario conjurar primero el movimiento del eterno retorno para lograr el salto cualitativo. Se reitera el mandato de Abundio al iniciar el camino hacia el Centro, lugar de las transformaciones: "¡Busque a doña Eduviges, si todavía vive!' (p. 71). Al hacerlo, se restablece un nexo con Abundio. Entre él y Juan Preciado se forma la cuerda que vincula lo bajo con lo alto en la tierra (véase el mandala espacial, supra). Sin transición, pasamos con Juan al "cuarto oscuro de la mujer", al espacio materno del nuevo nacimiento: una cama de otate (la madera es símbolo de la madre); "cubierta de costales" (envoltura materna de muerte, para poder renacer); "leño de la almohada" (lo materno proviene del agua, del sudor del cuerpo); olor a orines (fuego de la naturaleza interior que denota ausencia de sol); es decir ¿"nacimiento sin padre"?

Y la respiración de la mujer, "dispareja, como si estuviera entre sueños, más bien como si [ ...] sólo imitara los ruidos que produce el sueño" (p. 71). Claramente ésta indica la "asimilación del poder espiritual"'. Según Cirlot: "Los dos movimientos, positivo y negativo de la respiración, se asimilan a [...] las grandes vías de la involución y la evolución. La dificultad para respirar puede simbolizar así la de asimilar los principios espirituales y cósmi$\cos ^{\prime}{ }^{40}$. Lograr el "ritmo justo" es aproximarse a los "ritmos del universo".

A Juan Preciado se le revela la verdad del éxodo colectivo que caracteriza a un mundo lejos de su unidad primordial. El despedazamiento fue mostrado antes en el texto, con una imagen que impacta la sensibilidad: la figura "despedazada" de la madre de Pedro Páramo. Ahora las imágenes representan el sacrificio que

plen los cuatro requisitos fundamentales: 1) Es una historia larga o corta, en movimientos sucesivos (Integra narratio). 2) Encierra una verdad más alta. Su fuerza consiste en el salto de abajo hacia arriba (Veritas sublimior). 3) Tiene una simbología concreta, símbolos agrícolas, del trabajo humano, de la relación del padre con el hijo, etc. Son todos "elementos figurativos sensibles", lo cual facilita su expresión plástica o narrativa (Figurato modo). 4) Trabajo sobre los paralelismos, proporciones y oposiciones, ya que entre la realidad terrestre, visible, y la verdad más alta hay un paralelismo de semejanza o de oposición; cf. CARlos MARÍA MARTini, ¿Por qué Jesús hablaba en parábolas?, trad. Justiniano Beltrán, Eds. Paulinas, Bogotá, 1986, pp. 91-93.

${ }^{40}$ J.E. CiRLOT, op. cit., s.v. respiración. 
da origen al mundo, y desembocan en la inversión que realiza la unidad ${ }^{41}$.

Como los símbolos del vientre materno, la imagen reiterada y crecida revela la plenitud de la reintegración al concluir el fragmento: "Un cielo negro, lleno de estrellas. Y junto a la luna la estrella más grande de todas"' (p. 73).

En torno, la multitud de estrellas indica el ejército espiritual en lucha contra las tinieblas, que preconizó Eduviges ('la que lucha'). La estrella singular sólo está reservada al elegido (como la de Belén a Cristo).

La confirmación de la vía unitiva es evidente en el fragmento que sigue. Juan Preciado está en el espacio oral infinito de la voz de la madre. Se produce el mundo de la voz: sonoridad y sentido. No hace falta ver, porque se está en el principio del Verbo: “Su voz parecía abarcarlo todo. Se perdía más allá de la tierra' (id.). No la ve porque ella es el espacio mismo desmaterializado; onda sonora.

Juan Preciado se acuesta con la mujer. Se produce entonces una liberación de toda la materia telúrica que la cubre. La mujer se derrite en un charco de lodo y sudor en el que nada y se ahoga, por falta de aire, Juan Preciado. El espíritu se libera de la materia (¿liberación de la culpa original de este mundo condenado? Y consecuentemente, ¿posible liberación de la tierra?). Juan guarda memoria de "nubes espumosas haciendo remolino sobre mi cabeza y luego enjuagarme con aquella espuma y perderme en su nublazón"' (p. 74). Las nubes, siempre sujetas a las transformaciones y al movimiento, "esconden la identidad perenne de la verdad superior". Ellas posibilitan "la más alta sublimación, por una disolución en el cenit, en el cielo azul" "42. Por eso se arremolinan sobre su cabeza y la espuma lo cubre, lo baña y lo mete dentro de sí, como en el pasaje anterior la voz de la madre. Nuevo bautismo en el cual el binomio madre-hijo ha hecho posible la llegada del Espíritu.

Fragmentos 37-39. Equilibrio y signos renovadores

La tríada siguiente constituye otro núcleo de sentido que lleva a su meseta este primer movimiento. Es el momento del equilibrio

41 Se trata de un acto para "reconstituir lo despedazado" y regresar a la unidad; ibid., s.v. reunión.

42 G. Bachelard, op. cit.; p. 239. Véase también J.E. Cirlot, op. cit., s.v. nubes. 
dinámico de la espera, con la certeza de una nueva vida: los enunciados conjuntos de Juan Preciado y Dorotea (como los de Juan Preciado con los de su madre al comienzo de la novela) cercan el mundo condenado a desaparecer; lo envuelven, ahora sí, fuera del tiempo y en todo tiempo.

El núcleo de significación se distribuye del modo siguiente:

arriba-ahora

Unión espiritual

(madre-hijo)

Juan: el amor espiritual

Dorotea: el deseo colmado

del hijo salvador

MUNDO MATERNO ESPIRITUAL

(capaz de generar un mundo

nuevo: el del Hijo) abajo-antes

La Historia opresora

- El despojo de las tierras

- El desenfreno (la mercantilización

del amor; el crimen fraterno)

- El desprecio por el pueblo

- Entre la ley (Pedro Páramo)

y la práctica (Fulgor) se anula

el futuro (Miguel Páramo)

MUNDO PATRIARCAL MATERIALIZADO

(condenado a desaparecer)

3

arriba-después

Signos renovadores

Cambios audibles en la tierra arriba

Figuración: la maternidad invertida (Juan

acoge a Dorotea)

MUNDO AMOROSO DEL HIJO

La muerte de Juan Preciado ha sido promovida por los agentes activos del mundo de la madre, y por la densidad de la culpa y la queja colectivas (despedazamiento del "pueblo de Dios"): sinfín de murmullos indefinidos y pesados que detienen el aire y sofocan la respiración. Una frase se aísla significativa. Toda la masa incontenible de murmullos se condensa en un ruego sordo que invade el cuerpo del elegido: "Ruega a Dios por nosotros". Petición colectiva ${ }^{43}$ del perdón que redime en un tiempo límite.

La verdad de Dorotea es haber centrado su vida en la ilusión de los sueños; hecho que no tiene cabida en el mundo organizado en torno a Pedro Páramo. Por eso su ilusión trasciende ese mundo y, en última instancia, anuncia el advenimiento del Hijo esperado, necesario al cambio por venir.

También Juan Preciado ha venido impulsado por una ilusión: encontrar la verdad del padre. Dorotea colma su deseo; Juan Preciado supera los límites del mundo patriarcal (su dualismo) y fa-

${ }^{43}$ El pasaje recuerda la gran confesión del pueblo en La feria de JUAN José Arreola, J. Mortiz, México, 1963, p. 90. 
cilita el advenimiento de una historia liberada. Se restituye la unidad del mundo interior y del nosotros, fundamento de la sociedad. Dorotea simboliza el cambio cualitativo de individuación. Lo reconoce Juan Preciado cuando sugiere su naturaleza andrógina ( $i$ criatura angélica que cumple el destino que su nombre indica?):

- Tienes razón, Doroteo. ¿Dices que te llamas Doroteo? mismo.

-Da lo mismo. Aunque mi nombre sea Dorotea. Pero da lo

- Es cierto, Dorotea. Me mataron los murmullos (p. 75).

Los nombres adquieren su justo peso: Juan 'el predilecto' de Jesús, cuyo evangelio busca conciliar los dualismos en una mística de la unidad y del amor fraterno; Dorotea 'don de Dios', asociado también a Donato y Natanael. La historia de este último se liga con la promesa de la conjunción espiritual de la tierra y el cielo, mediante la acción de las criaturas angélicas de Dios: "Sí, les aseguro que verán el cielo abierto y a los ángeles de Dios subir, y bajar por este Hombre' 44 .

Es el texto oculto del evangelio de Juan.

Segundo movimiento. El dualismo de la tierra y la búsqueda del Centro

La escritura recomienza la historia de la caída individual y colectiva. El punto de vista dominante en todo este movimiento es, como ya indiqué, el de un narrador en tercera persona que relata la historia pasada del otro. Pero lo hace desde una perspectiva cercana que actualiza los hechos ante el lector. Se logra el doble efecto necesario: negarle la voz a Pedro Páramo (hablar sobre él desde un saber de lo alto), y convertirnos a los lectores en testigos presenciales de la caída.

Sabemos que la negación del amor y la muerte ha consolidado una personalidad escindida en Pedro Páramo, que concluye con la muerte de la carne y el vacío del espíritu. Ahora importa presenciar el proceso gradual de descomposición, sin retorno posible a la unidad, del personaje y su mundo.

Este segundo movimiento, ubicado en un tiempo anterior al primero, contiene rasgos de composición similares, regidos por un signo de inversión liberadora (en el ámbito de la historia pa-

${ }^{44} \mathrm{Jn} 1,51$. 
triarcal también de la muerte renacerá la vida: están los signos y explicaciones que motivan el primer movimiento). El mundo del hijo se prepara en el del padre, gracias a la imaginación dinámica que produce imágenes y símbolos ascensionales propios del espíritu (aire y sonoridad, fuego purificador) y del reino de la madre (sensibilidad, intuición, el agua y la tierra). Estos elementos crean las contradicciones necesarias para dar el cambio cualitativo, radical, que modifique el rumbo histórico. El lenguaje objetiva, sin embargo, el predominio del mundo patriarcal en este segundo movimiento, aunque se matice conforme actúan las tendencias opuestas. Comparado con el primer movimiento, el lenguaje es más reflexivo y racional. Nace de la "sabiduría del padre". El estilo lo manifiesta de manera ejemplar: el carácter reflexivo del enunciado se entrevera con locuciones y dichos de la filosofía popular. Además, cada personaje revelará su verdad: su función en la historia.

En cambio, si bien llegamos a conocer la fuerza telúrica y vital del lenguaje de Susana San Juan (no exento de racionalidad), es sólo gracias al narrador omnisciente. En el mundo patriarcal opresor, Susana deberá encerrarse en sí misma o en los signos del lenguaje corporal. Porque la hemos "oído" en el primer movimiento, se crea un contraste revelador para entender el cambio que se ha operado.

Fragmentos 40-43. El mundo del Padre. Caída y signos de renovación

Los dos primeros fragmentos se inician con una premonición de Pedro Páramo, quien evoca la muerte de su padre sugerida por una serie de indicios auditivos que tiene la pesantez de un mundo descendente de ritmo lento:

Rumor de voces. Arrastrar de pisadas despaciosas como si cargaran con algo pesado.

Ruidos vagos (p. 86).

Compárese con el fragmento 29, que precede a la entrada de Juan Preciado al Centro e integra el tono melancólico propio del tiempo materno, con un ritmo más ágil y una atmósfera presidida por el canto.

Los ruidos traen a la memoria la muerte del padre de Pedro Páramo (Lucas Páramo) en un tiempo análogo ("un amanecer como éste"). Una diferencia marcada es que entonces aún "la 
puerta estaba abierta y traslucía el color gris de un cielo [...]" (id.). Además, la explicación de la imagen materna se alarga. Si primero fue el desplazamiento visual de la figura corpórea, ahora es lo audible lo que importa. La voz (es decir, la manifestación del espíritu) es lo fracturado hasta los niveles mínimos: "Con aquella voz quebrada, deshecha, sólo unida por el hilo del sollozo", (id.). Si el recuerdo de la madre fue el impulso dominante para lograr el nuevo nacimiento, ahora lo que prevalece sobre el recuerdo reiterado es el olvido: "Una madre de la que él ya se habia olvidado y olvidado muchas veces, diciéndole: «HHan matado a tu padre!"” (id.). Matar al padre implica, pues, matar el cuerpo, la memoria y el alma.

Este proceso de Pedro Páramo se expresa en su lenguaje. Existe un contraste irreconciliable entre el estilo evocador y poético del discurso de Pedro Páramo que se refiere al objeto ideal (Susana San Juan) y el estilo del cacique de la Media Luna, que muestra el endurecimiento del personaje.

El resultado es una espiral de muertes cuyo vértice es la imagen del rostro paterno despedazado, tal como lo había anunciado el hijo campesino en el cuento “ ¡Díles que no me maten!” 45 . La idea de espiral subyace en la de la fuerza incontenible de la muerte, objetivada en una imagen agrícola y una expresión popular. Todo el pasaje, desde la imagen comentada antes, es de una economía poética extraordinaria:

Nunca quiso revivir ese recuerdo porque le traía otros, como si rompiera un costal repleto y luego quisiera contener el grano. La muerte de su padre que arrastró otras muertes y en cada una de ellas estaba siempre la imagen de la cara despedazada; roto un ojo, mirando vengativo el otro. Y otro y otro más, hasta que la habia borrado del recuerdo cuando ya no hubo nadie que se la recordara (pp. 86-87).

La vida histórica de Pedro Páramo será la ampliación de esa imagen. Le será negado, en consecuencia, el heroísmo e incluso el patetismo o el carácter trágico, aunque su vida participe de todos estos elementos. El temple de ánimo que exige una respuesta heroica ante el dolor, se convierte en aridez y endurecimiento, provenientes de la tensión progresiva entre el mundo ideal y el

45 "-Tu nuera y los nietos te extrañarán- iba diciéndole-. Te mirarán a la cara y creerán que no eres tú. Se les afigurará que te ha comido el coyote, cuando te vean con esa cara tan llena de boquetes por tanto tiro de gracia como te dieron", El llano.., p. 109. 
quehacer del hombre en el presente. Es que el ideal está sujeto a una experiencia del pasado, ya superada, que entorpece la entrada en la historia: el quehacer y el sentido del presente. Se produce el vacío" ${ }^{46}$. Los polos se tensan cada vez más hasta "romper las cuerdas", lo cual provoca la muerte por "despedazamiento" del personaje. Motivos todos que se encuentran diseminados por el texto ${ }^{47}$.

No obstante, y justo antes de la caída definitiva, la voluntad logra ofrecer un contrapunto que humaniza lo suficiente al personaje para no sentir abstracto su sentido (la oposición necesaria a la caída). Pedro Páramo se adueña de su muerte y la asume como expiación de su culpa: "Estoy comenzando a pagar. Más vale empezar temprano para terminar pronto" (p. 88). Al hacerlo, sin embargo, no libera el espíritu. Más bien se endurece e insensibiliza ante el presente, lo cual produce la ruptura y escisión del espíritu (los pensamientos despedazados). Lo que resta de vida, como vimos antes, se ata a una imagen del pasado, hecho que lo lleva necesariamente a la destrucción:

se había quedado sin expresión ninguna, como ido. Por encima de él sus pensamientos se seguían unos a otros sin darse alcance ni juntarse $[\ldots]$. No sintió dolor (id.).

El dinamismo vital (histórico) va dando paso a un mecanismo gestual que linda en lo grotesco ${ }^{48}$.

A la hora de la muerte, la tensión de los opuestos se hace intolerable. El único hilo que ata a Pedro Páramo a la vida es el recuerdo de Susana San Juan y éste se fija en una imagen celeste ( $¿$ de cuerpo glorificado?) que definitivamente escinde a Pedro Páramo del mundo de Susana: "«Ésta es mi muerte», dijo" (p. 158). Después sólo queda el recuerdo de la culpa por el pecado contra el hijo (el reino del hijo; el pueblo que Abundio representa).

Magistralmente el texto indica un último síntoma de esfuerzo

${ }^{46}$ En La evolución creadora, Henri Bergson afirma: "La concepción de un vacío nace aquí cuando la conciencia, en retraso consigo misma, permanece ligada al recuerdo de un estado antiguo siendo así que otro estado ya se hace presente"; en Obras escogidas, trad. y pról. de José Antonio Míguez, Aguilar, 1959, p. 681.

${ }^{47}$ Sobre estos motivos, véase George Ronald Freeman, op. cit, , partes 3.2 y 3.3 .

${ }_{48} \mathrm{Cf}$. Henri Bergson, La risa. Ensayo sobre la significación de lo cómico (1924), Losada, Buenos Aires, 1939, pp. 22 y 23. 
ascendente (más bien de respuesta sensible) que resulta inútil (mecánico), pero contrapuntea y subraya el desmoronamiento final.

Sintió que unas manos le tocaban los hombros y enderezó el cuerpo, endureciéndolo.

$[\ldots]$

Voy para allá. Yá voy.

$[\ldots]$

Hizo intento de caminar. Después de unos cuantos pasos cayó [...] y se fue desmoronando como si fuera un montón de piedras (p. 159).

Es la antítesis de Pedro, piedra fundadora, primado de los fieles del Evangelio de Juan, a quien se le pide una profesión de amor. Implica también la negación del binomio Pedro-Juan, fundador de las primeras comunidades fraternas.

No obstante, Dorotea reconoce la verdad del amor de Pedro Páramo por Susana San Juan, y adelanta la síntesis de todo el segundo movimiento (p. 103). Ella detenta la "verdad"' de la historia desde el punto de vista del pueblo, en casi todo el movimiento; desmitifica la visión desoladora de Susana San Juan sobre la muerte de su madre y tal vez se justifica a sí misma en la medida en que justifica al pueblo. Es el testigo y la mirada humanizadora.

Juan Preciado conoce ya la verdad del mundo de Pedro Páramo: el crimen, la mercantilización de la vida, la orfandad y el amor insatisfecho provocan su caída, la ruina de la tierra y la desbandada de los hombres. La caída, lenta y gradual, es definitiva: "Pero pasaron años y años y él seguía vivo, siempre allí, como un espantapájaros frente a las tierras de la Media Luna" (p. 104).

Se le niega el reposo vivificador de la tierra. En un mundo lunar propio de las sociedades agrícolas, la muerte "no es una extinción, sino una modificación [...] del nivel de la existencia [...] los difuntos pasan a la luna o regresan bajo la tierra a fin de regenerarse y de asimilar las fuerzas necesarias para una nueva existencia" 49 .

Si a Juan Preciado lo trae la ilusión, a Pedro Páramo lo extinguen la desilusión (p. 103) y la culpa. Por otra parte, la oposición que rige la vida de Pedro Páramo obliga al contrapunteo irónico, ya que sólo su muerte puede garantizar la vida de los otros. El texto expresa claramente la ambigüedad con el contrapunto que

${ }^{49}$ Mircea Eliade, op. cit., p. 165. 
se produce a la hora de la muerte de Susana San Juan entre la fiesta popular (símbolo de renovación) que se oye en la Media Luna, y la negación voluntaria de la historia que asume en el mismo momento Pedro Páramo, sordo al sentido del mundo de Susana San Juan, como veremos después: "-Me cruzaré de brazos y Comala se morirá de hambre. Y así lo hizo"' (p. 149).

Estructuralmente esta oposición se marca en el fragmento 66 (duplo de 33, indicativo de redención). El narrador se coloca en la Media Luna para oír desde ahí, sin perder su perspectiva de tercera persona ("allá"." acá"). El texto no pretende sustituir a la historia - el futuro queda siempre sólo sugerido en la novela-, pero sí detectar los nódulos de su germinación en el dinamismo dialéctico del presente y del pasado:

Allá había feria. Se jugaba a los gallos, se oía la música; los gritos de los borrachos y de las loterías. Hasta acá llegaba la luz del pueblo, que parecía una aureola sobre el cielo gris (id.).

\section{La historia. Pedro Páramo y Damiana Cisneros}

La negación histórica de Pedro Páramo se extiende a todo el sistema que representa y se simboliza en el espacio de la Media Luna. Es en ese espacio donde la Revolución toca a la puerta.

Damiana, la guardiana del lugar, presiente una fuerza nueva en la tierra (imagen lunar de transición) y llega a confirmar su presencia:

le pareció que la tierra estaba llena de hervores, como cuando ha llovido y se enchina de gusanos. Sentía que se levantaba algo así como el calor de muchos hombres. Oyó el croar de las ranas; los grillos; la noche quieta del tiempo de aguas. Luego volvió a oír los culatazos aporreando la puerta.

Una lámpara regó su luz sobre la cara de algunos hombres (p. 136).

No obstante, la saca de su vida, negándola: “"Son cosas que a mí no me interesan", dijo Damiana Cisneros y cerró la ventana" (p. 137). Parece escoger, como Pedro Páramo, la destrucción de su mundo. Incluso el texto permite verla como un centinela vigilante de que se cumpla el destino de Pedro Páramo. No hay que olvidar dos hechos que crean una ambigüedad suficiente: 1) Su negativa a Pedro Páramo en la juventud, que le da acceso a un lugar privilegiado de dominio en la Media Luna, y 2) el 
hecho de que ha sido la nodriza de Juan Preciado y lo recibe a su llegada, justo antes de pasar al Centro. También le dice a Juan Preciado que estuvo oyendo "muchas noches" los ruidos de la fiesta popular que, sin embargo, no le es dado ver (pp. 54-55).

Pedro Páramo pretende mediatizar la historia mercantilizándola y promoviendo la opresión entre los hombres. Una y otra vez la historia lo encara. El lector percibe el nexo dependiente entre el patrón y los hombres. Aquél se aprovecha desvirtuando su lucha. La "ayuda" de Pedro Páramo es más bien un mecanismo de sobrevivencia; como mucho, un último "fulgor" de su poder de mando. Pero precisamente porque no le importa abrirse al futuro, en sentido inverso al dinamismo del cambio histórico incipiente y confuso, se desgaja en su soledad. El contrapunto se aproxima al de vida y muerte. Por un lado, "Pedro Páramo miró cómo los hombres se iban. Sintió desfilar frente a él el trote de caballos oscuros, confundidos con la noche. El sudor y el polvo; el temblor de la tierra". Por otro, "se dio cuenta que todos los hombres se había ido. Quedaba él, solo, como un tronco duro comenzando a desgajarse por dentro" (pp. 138-139).

Se niega, refugiándose en el recuerdo "suyo" de la infancia compartida con Susana San Juan. El ideal, por abstracto, está condenado a no poder encarnar en un mundo enajenado de su sentido: "Y se había abrazado a ella [una muchachita que llama "puñadito de carne'"] tratando de convertirla en la carne de Susana San Juan: "Una mujer que no era de este mundo"” (p. 139).

No hay duda de que Pedro Páramo opta por detener su tiempo. Con él y en él el sistema se condena a sí mismo. El pueblo se desconcierta, pierde su raíz sin tener un objetivo claro para sustituirla. La "marca de Caín" será el resultado. No obstante, se reconoce un despertar violento en favor de la vida, a pesar del vacío, provocado por la tensión de las contradicciones estructurales.

Por eso los hombres transitoriamente suben y bajan de la Revolución a la Media Luna, sin clara conciencia de por qué lo hacen, pero impelidos a hacerlo buscando una salida. Es el propio sistema el que se niega a su transformación.

"El pueblo de Dios" y el padre Rentería

Finalmente, los hombres que han estado en la Revolución se van con el padre Rentería, quien opta por la lucha armada como una salida posible. El texto no condena la decisión; más bien muestra las contradicciones. El lector conoce el origen ambiguo de esa ac- 
ción producto de una conciencia culpable y desesperada (¿nuevo Judas? $)^{50}$. La autocrítica no es suficiente para dar una salida eficaz. La novela parece sugerir que, en última instancia, el problema es estructural e involucra al pueblo.

El "pecado" del padre Rentería, cuya confesión aparece en el fragmento 41, ha sido contra el Espíritu. No sin contradicciones y errores se ha prestado a la mercantilización de los sacramentos, lo cual explica su nombre; ha entregado al hijo, huérfano de madre, y que pudo ser su hijo del espíritu, al poder negador - por su práctica opresora- de la vida del Espíritu. Por eso su confesión (al lector) se da junto con la experiencia de la muerte de Miguel Páramo.

El sacerdote es víctima de su propia debilidad, a pesar de que ha sufrido en carne propia el crimen del hermano y la violación de su Iglesia (la sobrina y todas las mujeres que también son víctimas). Muestra también una inadecuación entre sus reflexiones y su acción, lo cual le produce un conflicto existencial evidente. De ahí la dificultad del perdón, negado por otro sacerdote.

La magnitud del pecado es grave. Sin embargo, toda la actitud del penitente y las circunstancias no permiten una condenación definitiva. La salida del texto es hábil. El sacerdote remite al padre Rentería a otro sacerdote, y al mismo tiempo se reconoce culpable, aunque en menor grado: "mis manos no son lo suficientemente limpias para darte la absolución" (p. 92). El diálogo de ambos reafirma la idea de que la situación de pecado los rebasa e incluye. El mal estructural conduce siempre al problema de la tierra. Por eso la escritura manifiesta la culpa social con los frutos de la tierra. Contla es una tierra fértil con frutos ácidos (p. 93) y Comala, un lugar donde "Sólo crecen arrayanes y naranjos agrios y arrayanes agrios", y donde las "semillas" del seminario mueren sin germinar. El texto deslinda la "voluntad de Dios", del mal social del latifundio.

- [...] dicen que las tierras de Comala son buenas. Es lástima que estén en manos de un solo hombre. ¿Es Pedro Páramo aún el dueño, no?

- Así es la voluntad de Dios.

- No creo que en este caso intervenga la voluntad de Dios (id.).

${ }^{50}$ Lo sugiero en la medida en que el pecado mayor de Judas Iscariote fue la desesperanza, hecho que lo conduce al suicidio. Otro indicio análogo es la mercantilización de lo sagrado en que ha incurrido el padre Rentería. 
De regreso a Comala, el padre Rentería le niega la posibilidad de ganar el cielo a Dorotea; la falta suya ha sido la complicidad (como el padre Rentería y Gerardo el abogado). Pero, a su vez, Dorotea representa el deseo del Hijo hasta el delirio: pide y anuncia, implícitamente, la llegada de Juan. Por eso ha ganado su lugar en los brazos del hijo y, gracias a él, es capaz de "oír", la verdad de este mundo. Representa la búsqueda (¿inconsciente?) del pueblo que necesita enfrentar la verdad de su historia para dejar de ser cómplice y redimirse. De ahí que hable a Juan Preciado del descubrimiento de su propia verdad y después de la de Pedro Páramo y su amor por Susana San Juan. Finalmente enfrenta con Juan Preciado la verdad de Susana San Juan.

$\mathrm{El}$ sacerdote sufre un proceso de inmersión en la culpa colectiva ("aquel mareo, aquella confusión, el irse diluyendo como en agua espesa, y el girar de luces; la luz entera del día que se desbarataba haciéndose añicos; y ese sabor a sangre en la lengua. El Yo pecador se oía más fuerte, repetido, y después terminaba: «por los siglos de los siglos, amén", "por los siglos de los siglos, amén", "por los siglos..."”, (p. 96).

El pueblo se arremolina y empoza en "un murmullo" (p. 97). Son los murmullos y confesiones que oye Juan Preciado antes de morir, cuya fuerza articuló el "Ruega a Dios por nosotros" colectivo. Juan está llamado a redimir la culpa del pueblo y de su pastor; víctima propiciatoria de esa urgencia colectiva de redención. Se refuerza el sentido de su sacrificio redentor, única salida histórica posible, de acuerdo con la novela.

\section{El pueblo. Pedro Páramo y Susana San Juan}

En Pédro Páramo el pueblo va conformando una imagen contradictoria pero de dinamismo ascendente, como el ritmo de la vida marcado por el texto. Al fallar el Padre, dentro de un sistema patriarcal, se despedaza el pueblo. El texto nos permite observar este proceso en los diálogos entre Pedro Páramo y sus hombres que se van a la Revolución, y en la relación del padre Rentería con su iglesia. Paralelamente al proceso de la caída que observamos en Pedro Páramo, sus hombres pierden el centro, pero capaces de actuar, se lanzan a la lucha con todas las contradicciones. Son los signos destructivos de un mundo solar fuera de su centro. El propio sistema, como hemos visto, se destruye a sí mismo. El padre Rentería se integra a la culpa, lo cual de algún modo mitiga su error histórico. 
Me detendré solamente en el núcleo de sentido que forman los fragmentos 67-69, los penúltimos de la novela. Una vez más, el sentido se ilumina en el fragmento central.

\section{Fragmento 68}

Pedro Páramo, sentado en su equipal, delata la cercanía de su muerte y su proceso de "expiación", sujeto al estatismo y al recuerdo de los pensamientos recurrentes sobre la muerte de Susana San Juan. Al estatismo de la muerte próxima y ¿anhelada? para liberarse de la conciencia, se contrapone el amanecer como una acción positiva sobre el mundo: "Amanecía" (p. 151).

Desde la óptica de Pedro Páramo se integran el amanecer de la muerte de Susana San Juan (que sigue "el camino del cielo") y el amanecer, en el presente, que implica su muerte. Al igualarlos, sugiere que la muerte de Susana supone la suya. Ella provoca $e l$ amanecer que lo destruye.

En la organización textual Susana es la mediadora para el pasaje de la vida a la muerte de Pedro Páramo. Antes, en el breve fragmento 67 se resumen los efectos de la venganza de Pedro Páramo contra Comala; su abandono: "Me cruzaré de brazos y Comala se morirá de hambre" (p. 149).

La fuerza de la decisión se manifiesta de inmediato en su actitud ante el proceso revolucionario en marcha ("El Tilcuate siguió viniendo", p. 150). Se reitera la relación filial, propia del sistema, que Pedro Páramo no aprovecha. Más bien propicia la salida de los hombres con el padre Rentería. Dejados a su libre arbitrio ("- Haz lo que quieras"), los hombres deciden irse con el sacerdote (el otro "padre") casi por inercia ("-Entonces, vete a descansar./- ¿Con el vuelo que tengo?", $i d$.$) .$

Fragmento 69. La inversión. La hora de Abundio y Susana San Juan

Por primera vez se dice en la novela el nombre completo de Abundio: "por la puerta entornada, se metió Abundio Martínez" (p. 151). Como Juan Preciado, lleva el apellido de su madre, y es precisamente una madre quien lo atiende al iniciarse el fragmento. Es un momento propicio al cambio. Las escenas 68 y 69 son simultáneas y quedan vinculadas a la hora de la muerte de Susana San Juan.

Abundio quiere decir 'abundante' o 'derramarse el agua por 


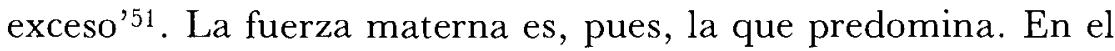
primer movimiento supimos que hubo un tiempo en que Abundio vivía a la altura de su nombre en el amor del pueblo. Era el "correo" entre el mundo de afuera y el mundo de adentro. La "desgracia" escinde su vida: pierde contacto con el mundo (simbólicamente ensordece el llamado a oír y a cantar); sufre todas las carencias afectivas y materiales (desconocido por el padre, sin descendencia y viudo, sin "Refugio"). Es abundante en necesidades, y por tanto, está capacitado para un destino trascendente conforme a la ley de la vida en el texto, de raíz cristiana, que de lo más bajo surgirá lo más alto. Su nombre se asocia además a la música popular, pues fue un compositor mexicano considerado muy bueno, autor de canciones populares muy conocidas quien, sin embargo, murió muy pobre y lleno de carencias. Rulfo juega con las asociaciones, ya que antes había anunciado la llegada de los nuevos tiempos con las canciones y quejas de amor provenientes de voces del pueblo.

Si bien Pedro Páramo es un muerto en vida, Abundio ejecuta el acto ritual de la muerte; la rubrica. Tiene razón Liliana Befumo Boschi al ver en Abundio al sacerdote del "sacrificio" 52 , aunque Rulfo se cuida de no rebasar la verosimilitud de la cotidianidad. El sentido brota en los intersticios de las palabras. Abundio -el abundante en aguas- representa también la náusea colectiva; el coraje acumulado que encuentra, por fin, salida ("vomitó una cosa amarilla como de bilis. Chorros y chorros [...]", p. 157). El texto es claro. El personaje se mueve "fuera de sí", borracho (versión disminuida de la borrachera como ritual de purificación), impulsado por una fuerza superior y por el deseo de la tierra, que resulta ser la cuerda que lo guía (¿Susana San Juan?): "Sentía que la tierra se retorcía [...] él corría para agarrarla, y cuando ya la tenía en sus manos se le volvía a ir, hasta que llegó frente a la figura de un señor sentado junto a una puerta" (p. 155). Toda la vida de miseria y orfandad se agoloa en su recuerdo inducido por el grito de Damiana Cisneros (p. 156) ${ }^{53}$.

51 Gutierre Tibón, op. cit., s.v. Abundio.

52 Así lo afirma: "Abundio [...] será el encargado de que se cumpla el sacrificio de Pedro Páramo. El alcohol, la soledad abismal en que se halla ante la muerte de su mujer, la indiferencia general, todo origina el desequilibrio que lo conduce al Caos y lo convierte en el sacerdote elegido para cumplir la ceremonia ritual'"; en op. cit., pp. 202-203.

${ }^{53}$ De acuerdo con G. Bachelard (op. cit., p. 281) se puede hablar de "una cosmología del grito [...] de una cosmología que reúne al ser en torno a un 
En el orden de la tierra (arriba), Abundio logra la inversión que Susana San Juan ha facilitado mediante su negación radical a formar una unidad (cuerpo y alma) con Pedro Páramo (unión que hubiese colmado el vacio producto de la escisión entre el mundo ideal y la praxis histórica del sector que representa Pedro Páramo.

Abundio cumple naturalmente el rito. Su gesto contrasta con el grito abismal de la guardiana de la Media Luna, quien pretende con su vade retro exorcizar el destino necesario de ese mundo histórico. Si bien queda un trazo del mundo mítico en Abundio (es cuidador de bestias de carga, lo cual permite asociarlo con una figura menor de los dioses genésicos del culto de la Gran Madre), me parece que Rulfo, al negarle su función procreadora (como efecto del sistema sobre él), satiriza esa relación por inadecuada al momento histórico en que se desarrollan los hechos. En cambio, el sentido cristiano (bajar para subir) devuelve al hombre su dignidad y da coherencia al acto.

Se aclara la razón por la cual el Abundio que guía a Juan Preciado cuando éste llega a Comala "oye" y vive en lo alto de los cerros (el punto más cercano entre la tierra y el cielo). Todo parece indicar que los " desposeídos de la tierra" están llamados a cumplir un destino liberador (como el Pelele de Señor Presidente de Asturias). En este caso, de la tierra. De ahí la relación de Abundio con Juan Preciado y Susana San Juan.

¿Qué significa Susana San Juan? Su lugar en la disposición textual

He mostrado primero el comienzo y el final de este segundo movimiento de la novela, y es evidente que todas las historias nos llevan a la de Susana San Juan.

$\mathrm{Su}$ proceso de transformación ocupa el mayor número de fragmentos y se encuentra en la parte central de este segundo movimiento. En el comienzo se recuerda la muerte de Pedro Páramo (el pasado) y la de Miguel Páramo (el futuro). En el final presenciamos la muerte de Pedro Páramo (el presente). Queda abolido el tiempo histórico para ese mundo condenado.

Susana San Juan, en cambio, se va definiendo en la novela como el principio necesario para lograr la unidad fecunda de la tierra, ahora despedazada.

Desde otro punto de vista, los tres primeros fragmentos (40-42)

grito. El grito es a la vez la primera realidad verbal y la primera realidad cosmogónica". 
de este segundo movimiento marcan tres mundos irreconciliables: el de Pedro Páramo (muerte, despojo y violación); el del padre Rentería (la mercantilización de lo sagrado y el pecado contra el hijo) y Susana San Juan ("fuente [...] de fuerza, de "alma» y de fecundidad como la tierra madre"') $)^{54}$.

Fragmento 42 (múltiplo de tres) indicativo del mundo de Juan

En el presente de la novela Susana, como Juan Preciado, es dueña de su discurso. Su voz irrumpe con fuerza desmitificadora. Pasa a primer plano una imagen ideal, deseada (el recuerdo materno acogedor, p. 97), encubridora de la verdad histórica. El objeto del deseo está negado por la historia personal y colectiva. Esto equivale, en el mundo de Pedro Páramo, a la negación de la madre como parte integral de la trinidad fundadora (Jung): se niega, pues, la fecundidad de toda la tierra; el lazo unitario entre los hombres; la sensibilidad y la protección acogedora; el ritmo pausado de la vida.

El juicio es categórico ("Pero esto es falso", id.), porque en el mundo de Pedro Páramo se ha olvidado hasta la muerte de la madre ("_ ¿Y a ti quién te mató, madre?", p. 34). Por eso Susana San Juan, después Doloritas, están obligadas a salir. Su hora es el futuro y se gestará afuera. Se contraponen las dos imágenes: la de la vida (binomio madre-hija) y la de la muerte (hija). Pero además las palabras sugieren algo más profundo. La ausencia de la madre obliga a Susana San Juan (figura del Centro; conjunción de la pureza y el amor que corresponde al principio femenino, de acuerdo con su nombre $)^{55}$ a asumir también el discurso de la verdad y del juicio, proveniente de la conciencia (el principio masculino). El texto lo objetiva con dos palabras clave planteadas como opuestos inicialmente: sentir (lo femenino)-pensar (lo masculino), y que luego sintetiza: "Siento el lugar en que estoy y pienso" (p. 97). Son los signos del mundo de Juan por venir: la superación de los dualismos sin cancelar los opuestos; la perfección dinámica del amor. El alma de la tierra reúne los contrarios; tendrá la fuerza del principio telúrico porque se eleva a principio religioso ${ }^{56}$. Esta transformación cualitativa hacia lo alto se irá ela-

${ }^{54}$ Mircea Eliade, op. cit., p. 228.

55 Susana proviene del hebreo Shushannah, de shus 'lirio blanco, azucena', y hannah 'gracia'. San Juan equivale a 'el amado' y el suyo es el evangelio del Amor (la caridad); véase Gutierre Tibón, op. cit., s.v. Susana, Juan.

56 "Antes de toda fabulación mítica referente a la tierra hubo la presencia 
borando en etapas sucesivas de purificación que implican, al mismo tiempo, las sucesivas caídas de Pedro Páramo hasta su muerte.

Lo que "piensa" Susana San Juan es la razón de la escisión histórica. En medio de una evocación del mundo paradisíaco de la infancia, se alude al abandono como la causa de la llegada de la esterilidad y de la muerte. Se reitera la imagen vital y fecunda de Dolores Preciado que acompaña a su hijo Juan al regreso; pero ahora se asume ya como un pasado, y se reconoce el cambio ocurrido:

Pienso cuando maduraban los limones. En el viento de febrero que rompía los tallos de los helechos, antes que el abandono los secara; los limones maduros que llenaban con su olor el viejo patio (pp. 97-98).

La imagen elaborada es paradigmática de una época regida por el dinamismo del aire, por lo alto (un mundo solar y aéreo positivo): luminosa, de cielo azul y viento que juega y limpia el polvo y las ramas. La alegría asciende con la risa de los pájaros: "Y los gorriones reían; picoteaban las hojas que el aire hacía caer, y reían; dejaban sus plumas entre las espinas de las ramas y perseguían mariposas y reían. Era esa época" (p. 98). Luego baja el tono y sintetiza: "En febrero, cuando las mañanas estaban llenas de viento, de gorriones y de luz azul" (id.). Para llegar al extremo de la pérdida: "Me acuerdo. Mi madre murió entonces". Y la muerte de la madre le permite darse cuenta del sentido oculto de la historia: la ausencia de solidaridad, la escisión entre su mundo y el pueblo, la mercantilización de los sacramentos, etc. (pp. 99-100).

El monólogo continúa como si hablara con Justina. Lo cierto es que habla en el submundo, donde la oye Juan Preciado. El texto marca la identidad entre Susana San Juan y Dolores Preciado. La mención del abandono nos lleva al discurso de Dolores en el primer fragmento de la novela. Oímos la orden (como quien está en el centro; la que dirige) que da a su hijo: "El olvido en que nos tuvo, mi hijo, cóbraselo caro" (p. 7). Es explícita la relación con el abandono marcado por Susana San Juan, cuando entendemos en el fragmento 9 que ese olvido es consecuencia del "abando-

misma del suelo, valorizado en el plano religioso [... ]. La estructura cósmica de la hierofanía de la tierra precedió a su estructura propiamente telúrica (que sólo se impuso definitivamente con la aparición de la agricultura)"'; MirCEA Eliade, op. cit., p. 223. 
no'. El recuerdo se actualiza precisamente en el diálogo de Juan con Eduviges sobre el nacimiento del primero, y la salida de Dolores Preciado con su hijo para Sayula (escisión que permite cumplir el destino del hijo por la mediación de la madre). En el pasado, Eduviges habla con Pedro Páramo y el diálogo suscita en Juan el recuerdo clave:

- ¿Pero de qué vivirán?

-Que Dios los asista.

...El abandono en que nos tuvo, mi hijo, cóbraselo caro (p. 27; las cursivas son del original).

Quiere decir que la muerte de la madre de Juan Preciado marca la hora de su salida para llegar a la verdad liberadora. Como antes, la muerte de la madre reveló a Susana San Juan los signos de muerte del mundo en que vivía, y marcó la llegada de su hora. Susana -y después Dolores Preciado- sale del lugar para cumplir su destino liberador (sale con Justina su nodriza y guardiana hasta su muerte, cf. p. 100).

El fragmento 9 (múltiplo de 3) estableció otro nexo que se aclara ahora al lector: Eduviges (ya casi aérea, fantasmal) lleva en su cuello una María Santísima del Refugio con un letrero que dice: "Refugio de pecadores". Refugio, la esposa-madre de Abundio (no tienen hijos y ella lo acoge y le da vida), cuya muerte lleva a Abundio a ejecutar su destino liberador.

Se une, pues, el destino del pueblo, necesitado de redención. Para lograrlo, se suman pasajes alusivos a la brujería que la escritura busca integrar en torno al nacimiento y destino de Juan Preciado, creando un cierto ámbito para el misterio. Como si se ne: cesitara una fuerza sincrética de todos los acercamientos al principio espiritual, aún dispersos y despedazados, pero llamados todos a conjugarse en un solo Espíritu de Verdad.

En el mundo telúrico, de signo lunar, subyace una solidaridad "cosmobiológica" que liga a

la vegetación, el reino animal y a los hombres de cierta región con el suelo que los ha producido y que los sostiene y alimenta [...]. La solidaridad [... ] se debe a la vida que es la misma en todas partes [...]. Cuando uno cualquiera de los modos de esa vida es mancillado o esterilizado por un crimen contra la vida, todos los otros modos son alcanzados, en virtud de su solidaridad orgánica ${ }^{57}$.

57 Ibid., p. 234. 
Con esto se da el carácter unitario, orgánico, de la nacionalidad, principio que une a "los hombres del lugar".

Implícitamente (discurso omitido) se sugiere que en el mundo de Juan (el del Espíritu) hay una solidaridad equivalente, centrada en el Amor (fácilmente identificable con la noción cristiana del Cuerpo Místico).

A partir de esta concepción, se entiende que Susana es la Gran Madre tierra que se proyecta en la madre (Dolores Preciado) para destruir el mundo patriarcal signado por el abandono de la tierra y de los hombres (mujeres e hijos). Por eso se homologan los discursos de ambas (Susana-Dolores) en el presente, y ante Juan Preciado (el que sabe oír; el que busca la verdad que los signos ocultan).

\section{Las transformaciones de Susana San Juan. El génesis}

En orden a cumplir su destino, Susana San Juan sufre varias transformaciones, acordes con su naturaleza sujeta a ciclos y a cambios. Se forjará así el polo dialéctico necesario para que pueda darse una historia, en esta tierra, a la altura del hombre. La primera de estas transformaciones es su conversión en el alma de la tierra. Los elementos simbólicos que manifiestan la transmutación son: el baño en el agua (lo femenino) con Pedro Páramo en la infancia, y la unión de ambos en el aire (lo masculino) con el vuelo de los papalotes, el cual sugiere la necesidad de una orientación trascendente.

Conviene recordar que la Madre-tierra necesita unirse al principio masculino, en el estadio previo al nivel superior (la tierra autogeneradora y sagrada).

Al salir del espacio, Susana San Juan supera ese vínculo inicial (que corresponde al apogeo histórico del latifundio), al cual queda atado Pedro Páramo, quien niega la historia del porvenir.

Susana llega a conjugar en sí misma los contrarios (principio telúrico generador de vida). El mediador es su padre, Bartolomé San Juan, como primero lo fue su madre. Al dinamismo general de lo femenino o de lo espiritual puro se integra el principio de organización y construcción, vinculado al intelecto y a la razón, precisamente en el fragmento 44 (símbolo doble de la cuaternidad $)^{58}$. 
Fragmentos 44-47. Susana y Bartolomé San Juan. La tierra

Es Fulgor (la acción en el mundo de Pedro Páramo, que es la decisión) el que sugiere una relación simbiótica entre Susana San Juan y su padre, por lo cual la identifica a ella, implícitamente, con la madre.

Esta imagen se produce en el lugar de la tercera transformación, como se verá después en el fragmento 46. Paralelamente - como si la reforzara- se da la descripción del refugio "materno"' de Bartolomé San Juan y Susana, propicio a un nacimiento, y los vientos - "raros", según Pedro Páramo- que soplan de la "gente levantada en armas". El nuevo nacimiento se relaciona con el proceso de liberación popular.

Bartolomé San Juan, como lo indica su nombre, es "hijo abundante en surcos" de la vida del Espíritu. Además es minero; está llamado a dominar el sentido integral de la tierra (su arriba y su abajo en interrelación). Tiene el sentido de la historia de su pueblo, lo cual lo asocia con Bartolomé, el discípulo alabado por Jesús a quien se identifica como el 'verdadero israelita' por su autenticidad nacional $^{59}$. Si la muerte de la madre le hizo cobrar conciencia a Susana de problemas sociales específicos, su unión con el padre le permitirá conocer el sentido último de ese mundo.

Bartolomé profetiza su muerte necesaria (su martirio como el Bartolomé evangélico) y define a Susana por su filiación a él: "Tú eres mi hija. Mía. Hija de Bartolomé San Juan' ' (p. 108). Su mundo (conocedor de la tierra) se opone al de Pedro Páramo ("Es la pura maldad. Eso es Pedro Páramo', id.).

Bartolomé San Juan enuncia la verdad de ese mundo de opresión al que parece estar sujeta por el momento Susana, que pulveriza y despedaza "como si se rociara la tierra con nuestra sangre" (id.). Es decir, condenado a la esterilidad y a la muerte por el sacrilegio del crimen contra la vida que lo funda.

Juan Preciado ha tenido una revelación análoga, pero en boca de una de las víctimas de Pedro Páramo (nótese que Juan nunca oye o habla con las figuras paternas que viene a sustituir). La voz de la víctima narra lo sucedido. Su relato está dirigido a todo interlocutor y, por excesivo, linda en lo grotesco. Más que el charco de sangre en que cayó la víctima, sobrecoge el contrapunto discursivo del hombre que, aterrado, cae en una actitud servil que 
pretende excusar a su agresor. Peor que la mutilación física, es la disminución de la persona (cf. p. 102).

No obstante, en el orden simbólico lo que importa es la sangre derramada, pues ella denuncia la gravedad del pecado de Pedro Páramo contra la tierra y el hombre, y constituye la razón de ser de su castigo:

Tenía sangre por todas partes. Y al enderezarme chapotié con mis manos la sangre regada en las piedras. Y era mía. Montonales de sangre. Pero no estaba muerto. Me di cuenta. Supe que don Pedro no tenía intenciones de matarme. Sólo de darme un susto (pp. 101-102).

Se trata de un sacrilegio porque "la sangre "vertida" envenena la tierra. Y la calamidad se manifiesta en el hecho de que los campos, los animales y los hombres quedan igualmente heridos de esterilidad". En cambio, el poder basado en la justicia asegura "la fertilidad de la tierra, de los animales y de las mujeres" 60 . Somos nosotros lectores los que unimos el enunciado esencial de Bartolomé San Juan con la denuncia de la víctima.

Por eso la escritura puede ahorrar caminos a la explicación racional. En la medida en que Bartolomé enfrenta a Susana a la verdad en el fragmento 46, ella se protege en la locura; se enajena del presente. El texto lo sugiere de modo ejemplar. En Susana hay un cambio del ritmo lento y sucesivo del pensamiento racional al vértigo de las ideas (cf. p. 108). Y concluye el fragmento con este diálogo entre padre e hija:

- ¿Estás loca?

-Claro que sí, Bartolomé. ¿No lo sabías? (p. 109).

Y en efecto (fragmento 47), Pedro Páramo decide la muerte de Bartolomé San Juan y Fulgor la ejecuta. Nuevamente es el binomio de la muerte que saca a Pedro Páramo definitivamente de la vida.

\section{Fragmentos 48-51}

Estos cuatro fragmentos forman un núcleo sobre $e l$ sentido y la muerte de Susana San Juan. Lo inicia una "lluvia menuda, extraña para 
estas tierras", "la tierra anegada, bajo la lluvia" (p. 110). Luego lo cierra un viento tan pertinaz como la lluvia que lo había traído (cf. p. 117).

La lluvia es un símbolo vital y celeste. Tiene sentido de fertilización y purificación, acepciones todas que se manifiestan en estos pasajes. Completa el símbolo la presencia de los indígenas el día de mercado: pueblo lleno de carencias pero capaz todavía de reír y de esperar el tiempo que vendrá. El viento, a su vez, es el aspecto activo, violento, del aire. Se le considera el primer elemento por su asimilación al "soplo creador" 61 . La agonía de Susana San Juan está entreverada con la muerte de su padre que ronda (sensación de que es un gato que se mete entre sus pies, como antes los gatos acompañaban a Dolores Preciado cuando estaba en la Media Luna - ¿tenue hilo con Aura de Carlos Fuentes?).

$\mathrm{El}$ anuncio de la muerte del padre provoca una retrospectiva en la que se revela la segunda transformación de Susana San Juan, también en la niñez, y que seguramente en el nivel simbólico logra la ruptura con el mundo de Pedro Páramo y establece una unión con el alma de la tierra (su sentido) y el mundo de Bartolomé San Juan. Éste le pide que baje hasta lo más profundo de un pozo y la insta a buscar oro allí. Es decir, el corazón de la tierra, su sentido último. Susana baja atada al exterior sólo por una cuerda que "le lastimaba la cintura, que le sangraba las manos; pero que no quería soltar" (p. 116). En la otra punta de la cuerda está su padre. El acto es un pasaje de salvación en la simbología cristiana. del pozo, que templa al personaje. Por eso despierta entre las miradas de hielo de su padre (el hielo fija su sentido simbólico; le da dureza y resistencia "contra lo inferior" y, en tanto frío, sugiere $l o$ alto62). Lo que encuentra en el seno de la tierra es una "calavera de muerto" que entrega a su padre "pedazo a pedazo". El padre la obliga a ver y a buscar la verdad, y establece con ella una liga profunda que va de la muerte a la vida (la cuerda). La descripción del cadáver (que Susana debe entregar al padre) simboliza y anuncia la muerte de Pedro Páramo y lo identifica con el destino de la tierra:

El cadáver se deshizo en canillas; la quijada se desprendió como si fuera de azúcar. Le fue dando pedazo a pedazo hasta que llegó a los dedos de los pies y lo entregó coyuntura tras coyuntura. $Y$ la

61 J.E. Cirlot, op. cit., s.v. viento.

62 Ibid., s.v. hielo. 
calavera primero; aquella bola redonda que se deshizo entre sus manos (p. 117).

La "calavera primero" indica la voluntad de entregar lo que resta del ser vivo después de destruido su cuerpo. Deshecho el "vaso de la vida y del pensamiento", no quedará nada. El ritual de la muerte es lento y pulverizador. Susana San Juan está destinada a realizarlo para liberar la tierra. El rito que ha vivido le ha dado la curación de un nuevo nacimiento ${ }^{63}$, clave para lograr la transformación necesaria del mundo: habrá que partir de una transformación radical del "centro". Por ahora, es necesario destruir el centro activo en la superficie de la historia: Pedro Páramo (la cabeza).

En el fragmento 51 se marca la incomunicación entre el padre Rentería y Susana San Juan (atada a la tierra, al padre y al recuerdo de Florencio, su esposo).

Fragmentos 52 y 53. Pedro Páramo y Juan Preciado ante el mundo de Susana San Juan

Estos dos fragmentos son centrales para el sentido de los mundos en pugna. El 52 se inicia con la noticia de la muerte de Fulgor Sedano. La voz tartamuda que lo anuncia es desvalorizante. Lo es también la imagen de su muerte, representación satírica de ese mundo escindido de Pedro Páramo. El ejecutor ha sido el pueblo (revolucionario, oprimido y diezmado por Fulgor):

“CCocórrale! [...] ¡Vaya y dígale a su patrón que allá nos veremos!'”. Y él soltó la cacalda, despavorido. No muy de prisa, por lo pepesado que era. Pero cocorrió. Lo mataron cocorriendo. Murió cocon una pata arriba y otra abajo (p. 120).

Con Fulgor desaparece la proyección activa de Pedro Páramo. Sólo le queda, como ante un pozo, contemplar la muerte de Susana San Juan. Quedará fijado a ella en un proceso de despedazamiento progresivo que se resuelve, años después (tiempo de preparación de Juan Preciado), en su desmoronamiento.

Lo que contempla son gestos que no logra descifrar. El lector reconoce en ellos un proceso análogo al de la transformación de

63 Los pueblos agrícolas relacionan esta idea del nuevo nacimiento con la unión a la tierra-madre. Cf. Mircea Eliade, op. cit, , p. 231. 
Juan Preciado, que facilita la inversión y el cambio de la corriente vital y de las circunstancias:

observando a través de la pálida luz de la veladora el cuerpo en movimiento de Susana; la cara sudorosa, las manos agitando las sábanas, estrujando la almohada hasta el desmorecimiento (p. 121).

Si al menos hubiera sabido qué era aquello que la maltrataba por dentro, que la hacía revolcarse en el desvelo, como si la despedazaran hasta inutilizarla (p. 122).

La incomunicación crea el vacío entre el mundo de Pedro Páramo y el de Susana San Juan. El saber le es negado a Pedro Páramo porque él niega, con su vida, la esencia de Susana.

El fragmento siguiente está en el tiempo y espacio del presente. Susana San Juan habla y delata su sentido alto. Juan Preciado la oye. Él es el llamado a oír y a conocer la raíz del mundo de Susana San Juan, y enseña a Dorotea a oír.

Lo relatado por Susana San Juan es su proceso de purificación y transformación en el mar. Su gesto corporal forma el ícono quinario de la mujer universal que se une a la fuente de la vida y de la muerte, como regresar a la madre: "Tenía los ojos cerrados, los brazos abiertos, desdobladas las piernas a la brisa del mar" (p. 122). Susana logra la reunión del agua con la tierra. La mediación es Florencio su esposo. Se da la unión de los elementos en un bautismo que conlleva la "unión universal de las virtualidades". La inmersión en las aguas, que se repite, implica el pasaje por la muerte y la disolución, pero también el renacimiento con una mayor fuerza vital (muerte y sepultura; vida y resurrección), pero todavía sólo "simboliza la vida terrestre, la vida natural, nunca la vida metafísica" 64 .

Florencio 'el floreciente', simboliza la belleza y la primavera. Es el mediador (principio masculino necesario, pero transitorio) que facilita la conjunción de la tierra y del agua (integración del principio femenino). Pertenece al mundo de la flor, de Susana ('lirio blanco, azucena, llena de gracia'), lo que equivale a decir que pertenece al Centro y que al conjugarse ambos forman la imagen arquetípica del alma de la tierra ${ }^{65}$.

${ }^{64} \mathrm{~J}$.E. Cirlot, op. cit., s.v. agua.

${ }^{65}$ El texto es explícito en la función mediadora ¿o sólo catalizadora? de Florencio. La unión mítica y simbólica de Susana con el mar sólo la involucra a ella, en quien se da un proceso transformador cada vez más alto: "Él me siguió el primer día y se sintió solo, a pesar de estar yo allí [...]. Y se fue'. 
Cuatro (símbolo de la tierra) han sido las transformaciones de Susana San Juan: la primera, en la infancia, con Pedro Páramo; la del pozo, también en la infancia, promovida por el padre; la del mar con Florencio y la de la hora de la muerte (incorporación de lo sagrado, de lo celeste). La imagen de esta última transmutación la da, como señalé antes, Pedro Páramo antes de morir:

“...Había una luna grande en medio del mundo. Se me perdían los ojos mirándote. Los rayos de la luna filtrándose sobre tu cara. No me cansaba de ver esa aparición que eras tú. Suave, restregada de luna; tu boca abullonada, humedecida, irisada de estrellas; tu cuerpo transparentándose en el agua de la noche. Susana, Susana San Juan" (p. 158).

\section{Fragmentos 54-57. Otro núcleo cuaternario}

La oposición entre el modo como Pedro Páramo pretende utilizar la Revolución en su provecho, sin involucrarse (fragmentos 54 y 55), y su anhelo de Susana San Juan, llega a su límite. Pedro Páramo se incomunica cada vez más con el mundo vital, genésico de Susana. Por eso en estos fragmentos se contrastan la respuesta a la Revolución (a la historia) y el amor sexual de ella (el goce del cuerpo y la unión carnal - "dos en una sola carne") que se expresa en una suerte de himno a la vida, próximo a la experiencia mística de la vía unitiva que conlleva la pérdida de sí misma (pp. 127-128). A esta vivencia de lo alto le acompaña el lamento-reproche que nace de la fuerza terrible del deseo que sólo una experiencia colmada puede dejar:

¡Señor, tú no existes! Te pedí tu protección para él. Que me lo cuidaras. Eso te pedí. Pero tú te ocupas nada más de las almas. Y lo que yo quiero de él es su cuerpo. Desnudo y caliente de amor; hirviendo de deseos; estrujando el temblor de mis senos y de mis brazos. Mi cuerpo transparente suspendido del suyo. Mi cuerpo liviano sostenido y suelto a sus fuerzas. ¿Qué haré ahora con mis labios sin su boca para llenarlos? ¿Qué haré de mis adoloridos labios? (p. 129).

Al concluir el fragmento: "-Me gusta bañarme en el mar- le dije. /Pero él no lo comprendel. Y al otro día estaba otra vez en el mar, purificándome. Entregándome a sus olas"' (p. 123). 
El alma de la tierra ("transparente", "'liviana") reclama un cuerpo que la integre y la encarne. Se busca la asunción del principio masculino. A Pedro Páramo sólo le es dado contemplar el agitado sueño de Susana desde la superficie, sin que se rompa nunca, ante él, el silencio. Se le niega, incluso, la posibilidad de consolarla.

En cambio, Juan Preciado oye y comunica a Dorotea la exaltación de la unión sexual. En el mundo por venir los contrarios están llamados a conjugarse como pareja en cuerpo y alma. La imagen se objetiva con alusiones al símbolo de la comida sacramental: "el pan dorado" en el horno ${ }^{66}$, el calor que transforma, la sensación de un nuevo nacimiento y la identificación de la mujer con la tierra:

Que dormía acurrucada, metiéndose dentro de él, perdida en la nada al sentir que se quebraba su carne, que se abría como un surco abierto por un clavo ardoroso, luego tibio, luego dulce, dando golpes duros contra su carne blanda; sumiéndose, sumiéndose más hasta el gemido (pp. 127-128).

Evidentemente hay una coincidencia entre este discurso y el de la tierra fértil paradisíaca de Dolores Preciado. La identidad se nos marcó en las pp. 60-61, cuando Juan Preciado evoca el paso de las carretas, símbolo de la vida:

"[...] Llegan de todas partes, copeteadas de salitre, de mazorcas, de yerba de Pará... Es la misma hora en que se abren los hornos y huele a pan recién horneado. Y de pronto puede tronar el cielo. Caer la lluvia. Puede llegar la Primavera [... ] (p. 60).

Se restablece el ritmo vital (vida-muerte): "Pero le había dolido más su muerte. Eso dice"' (p. 128). La intensidad dolorosa de los polos vitales se equilibra.

El canto a la vida que adviene en el submundo inicia a Dorotea (profeta y testigo de la verdad, como la historia) para oír las voces de la vida nueva en gestación:

- Se ha de haber roto el cajón donde lo enterraron, porque se oye como un crujir de tablas.

-Sí, yo también lo oigo (id.).

${ }^{66} \mathrm{El}$ símbolo del horno indica la "pura gestación espiritual"; J.E. CiRLOT, s.v. horno. 
¿El crujir de dientes de la condenación es ahora el crujir de tablas de la fuerza del nuevo nacimiento de la tierra? La verdad de Susana San Juan queda ambigua como la vida. La escritura parece objetivar la imagen de la lucha de un alma aprisionada en la materia (sugerida por la relación con Andrómeda). El ritmo vital se refuerza como una oposición dialéctica de vida-muerte; cielo e infierno. Siempre el juego de los contrarios que el sujeto asume en favor de uno u otro, pero sin anularlos. Vida como tensión que se inclina hacia los caminos del amor o de la muerte, según lo determina, en libertad, el hombre.

\section{Fragmentos 62-65. Nuevo cuaternario}

Antes de morir (fragmento 62), Susana vive el infierno del alma aprisionada por las muertes y caídas sucesivas. No obstante, la naturaleza advierte que son tiempos de regeneración: "En el comienzo del amanecer [...] la vibración de esta tierra que vuelca su oscuridad"' (p. 139). Susana "oye", porque ha ganado el paso al nivel de la espera de la encarnación. Justina reconoce ese paso de un estado a otro:

- ¿Y qué crees que es la vida, Justina, sino un pecado? ¿No oyes? ¿No oyes como rechina la tierra?

- No, Susana, no alcanzo a oír nada. Mi suerte no es tan grande como la tuya (id.).

Todos son signos de nacimiento y renovación. El pueblo anuncia la liberación futura con la fiesta que surge en el horizonte y contrapuntea la muerte. La preparación para la Navidad (p. 143) se convierte en fiesta, porque el pueblo, cercano a la raíz, presiente lo que conllevan los signos de los tiempos.

Por eso el diálogo de dos mujeres del pueblo, que miran el paso de la luz en la Media Luna, es el que nos ubica en el tiempo histórico. La agonía ha durado tres años (¿¿la Cristíada?) y Susana muere un 8 de diciembre, día de la Inmaculada Concepción. El pueblo sabe que Pedro Páramo no entenderá los signos de renovación " [...] si alguien se muere en esa casa. Con el poder que tiene don Pedro, nos desbarataría la función [... ]"' (p. 143).

Porque el destino de Susana, después de su Pasión, es renacer, el fragmento 64 marca la barrera entre ella y el padre Rentería, que insiste en imágenes de muerte que erosiona y carcome el cuerpo, y la "visión de Dios" como el opuesto luminoso. 
Pero el padre Rentería la contempla, y a diferencia de Pedro Páramo, se acerca a la verdad: "Le entraron dudas. Quizá ella no tenía nada de qué arrepentirse. Tal vez no tenía nada de qué perdonarla"' (p. 147).

Ella es dueña de su muerte, como lo es ya de su voz en este segundo movimiento: "- ¡Ya váyase, padre! No se mortifique por mí. Estoy tranquila y tengo mucho sueño" (p. 147).

La muerte como sueño implica despertar (Susana San Juan); como desmoronamiento implica la disolución total (Pedro Páramo).

El pueblo (la historia) rubrica la muerte de Susana para que conste y se reconozca su resurrección futura. La voz de Dorotea lo atestigua: "-Yo. Yo vi morir a doña Susanita" (id.).

Y ver morir a Susana San Juan es contemplar el ícono del regreso al origen primero, volcarse en posición fetal en el infinito:

sintió que la cabeza se le clavaba en el vientre. Trató de separar el vientre de su cabeza; de hacer a un lado aquel vientre que le apretaba los ojos y le cortaba la respiración; pero cada vez se volcaba más como si se hundiera en la noche (id.).

Pasamos al círculo vital de la perfección; el logro de la unidad que supera los contrarios. Claramente se ha dado el paso alto al principio telúrico. Mediante la unión de lo masculino y de lo femenino (sabiduría e intuición; cielo y tierra), logra la unión perfecta. El mandala esta vez es el nuevo símbolo de la tierra. De la unión de los contrarios surge el círculo ${ }^{67}$ :

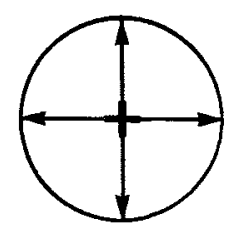

El submundo. Lugar de espera para renacer

Desbaratado el incesto (culpa original del mundo patriarcal), quedan en el submundo, lugar de los escogidos (¿para formar el "pueblo escogido"?): Juan Preciado y Dorotea; Susana San Juan; una

${ }^{67} \mathrm{R} . \mathrm{KocH}$, op. cit., pp. 3 y 50. 
víctima inocente de Pedro Páramo (todos y ninguno) y otros muertos.

Se ha ganado la vida perdurable, gracias a la presencia del Espíritu de la Verdad y del Amor (Juan Preciado) que da sentido a la Historia, informándola (Dorotea). La escisión (objetivada en el páramo de Pedro) ha sido superada por la unión de los contrarios. El murmullo-mugido de los muertos sin descanso por la culpa, se redime (la culpa colectiva ha llevado a Juan a morir como víctima propiciatoria para invertir el tiempo). Así el tiempo de la caída dará paso en la superficie al tiempo de la resurrección, mediante una transformación cualitativa de signo ascendente que supera la tendencia al tiempo cíclico reiterativo, trascendiendo el eterno retorno en un tiempo escatológico, de múltiples conversiones posibles, hasta el infinito.

Finalmente, si el mundo de la caída había envenenado la tierra debido a los vínculos orgánicos entre la naturaleza y los hombres, la llegada del mundo del Espíritu (del Hijo) conlleva la resurrección de la carne y la posibilidad de la comunión fraterna. Los une, sobre todo, la capacidad de oír los signos de los tiempos (predominio de lo sensible e intuitivo) y de vivir la plenitud de la carne y del espíritu (la búsqueda de la integración dinámica y liberadora).

La profesión de fe en el hombre y en el mundo, y su objetivo trascendente, se había marcado como respuesta ante la muerte, al comienzo de la novela, precisamente en un contexto de renovación manifestada en los símbolos de la noche, los relámpagos y "la lluvia que se convertía en brisa". Las sacerdotisas del acto de fe son las mujeres que cumplen el ritual con el ritmo pausado y la serenidad de la certeza. El testigo es Pedro Páramo en su infancia:

La lluvia se convertía en brisa. Oyó: "El perdón de los pecados y la resurrección de la carne. Amén". Eso era acá adentro, donde unas mujeres rezaban el final del rosario. Se levantaban; encerraban los pájaros; atrancaban la puerta; apartaban la luz (p. 21-22).

La novela cumple con la estructura que propone en su desplazamiento textual básico (dos ejes y un centro que los equilibra. De arriba a abajo llega Juan Preciado al Centro. De abajo a arriba llega Susana San Juan, y ambos se integran al cielo (lo superior). La imagen gráfica del libro y del sentido es la de la cruz en dos dimensiones: 


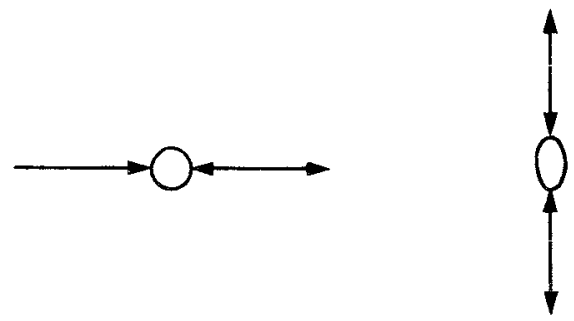

El cenit, es decir, el paso del mundo de la manifestación (espacial y temporal) al de la eternidad, suele identificarse con el centro de la cruz tridimensional ('corazón del espacio'). Pero cabe reducir simbólicamente la cruz a dos dimensiones de tal forma que represente la "armonía" entre lo "ancho"' (la amplitud, la historia) y lo "alto" (la exaltación trascendente). "El sentido horizontal, dice Cirlot, concierne a las posibilidades de un grado o momento de la existencia'". El vertical, a su elevación moral. Pero además el trazo vertical representa la unicidad de Dios, su cabeza (principio rector necesario); también simboliza el poder que desciende sobre la humanidad desde lo alto, y de abajo arriba, el anhelo de la humanidad por las cosas más altas ${ }^{68}$.

La escritura refuerza este desciframiento con la figuración que marca de Pedro Páramo. Desde el comienzo de la novela, como vimos antes, Pedro Páramo es un personaje escindido entre dos polos diametralmente opuestos: el mundo ideal y el mundo material del quehacer histórico de dominio, propio del mundo patriarcal (el alma y el cuerpo; lo alto y lo bajo). La verdad de esa escisión (la orfandad y el desamor) es su ruptura con el Centro que condena al vacío y despedaza:

$$
1
$$

En el plano de la historia, la escisión inicial correspondería (aunque no exclusivamente) a la ruptura entre el mundo criollo y el indígena (en los Altos de Jalisco y en otros puntos nodales del país). Precisamente a la hora de la transformación celeste de Susana San Juan, cae la lluvia renovadora y los indígenas ( $\dot{c}$ el alma de la raza, no integrada?) esperan su hora. Se sugiere en ellos

${ }^{68}$ J.E. Cirlot; op. cit., s.v. espacio; véase también $\mathrm{Koch}$, op. cit., p. 1. 
la presencia de una fuerza espiritual (la risa, la esperanza, el ritmo pausado) que contrasta con lo diezmado de sus posibilidades de sobrevivencia. Son los llamados a la transformación que destaca el texto.

Justina baja de la Media Luna y, al hacerlo, delata y subraya, por contraste, la escisión entre ambos mundos (p. 111). ¿Parte de aquí el proyecto de Juan José Arreola en La feria, de 1963? Tres años después de La feria, José Emilio Pacheco transforma creativamente en la Babel citadina del Distrito Federal, y en un contexto universal explícito la propuesta de Juan Rulfo, en su novela Morirás lejos, escrita en 1966 y publicada por primera vez en 1967. Pacheco narra la historia del pueblo judío, escindido y diezmado por la opresión del poder absoluto - y con él todos los pueblos que sufren una situación histórica análoga. El poder absoluto, como en Pedro Páramo, se condena sin alternativa de redención, no obstante que el texto muestra que es víctima y victimario al mismo tiempo. A diferencia de Pedro Páramo, Morirás lejos limita la solución a la unión de los contrarios (mujer y hombre, la $\mathrm{Hu}$ manidad armónica), sin el carácter trascendente de la historia y del hombre que tiene la novela de Rulfo.

Antes en "Luvina", y ahora en la novela, se insiste en la necesidad de integrar el mundo de adentro con el de afuera (de Comala a Sayula, y de Sayula al mundo), donde hay signos vitales evidentes (recuérdese la función de Abundio). Es decir, por un lado se indica la necesidad de integrar las partes escindidas del territorio nacional (escisión que se ha dado en la historia desde la Colonia, y se repite en el momento de la Revolución en los Altos de Jalisco, por ejemplo), y por otro, se sugiere (y se objetiva en la relación con otros textos) la necesidad de abrirse a los signos fertilizantes de un contexto universal.

Tanto en los cuentos como en la novela, Juan Rulfo trabaja como un descifrador de los signos de la cotidianidad, atento al sentido que trazan en su devenir de apariencia muchas veces anónima y sin sentido. Describe así ante nuestros ojos la grandeza de lo "pequeño": el contrapunto armonioso del poder opresor y deshumanizado. Le preocupa el hombre de todos los días como el símbolo viviente de la verdad última del sistema. Su obra no es tanto una anatomía del poder, cuanto un registro de sus efectos sobre el hombre entendido como pueblo, y no como individuo aislado. Por eso, si la tierra deja de estar al servicio de todos, y se desnaturalizan sus fines, está condenada al páramo y a la esterilidad. 
En última instancia, además, el pueblo es el sujeto de la historia. Ningún poder ajeno a esta verdad podrá crear alternativas válidas para las transformaciones necesarias. Una y otra vez la novela nos insta a ver lo omitido, lo oculto, y sobre todo, a oír esa queja anónima que repite sin fin la denuncia y la culpa colectivas. Pero no basta la denuncia. El texto enseña a oír y a ver los signos esperanzadores entreverados con los de la caída. No es un registro de hechos (que dejaría despedazada la visión). Desde la perspectiva de un pueblo con un destino solidario y trascendente se enjuicia, "por añadidura" y, por eso mismo, en su "verdad", la historia.

Pedro Páramo es la tierra producto de un sistema que pierde, precisamente, su sentido natural y se prostituye. Susana San Juan es el principio telúrico, el fruto y el potencial de vida negado a esa tierra.

YvetTe Jiménez de BÁEZ

El Colegio de México 